Check for updates

Cite this: Phys. Chem. Chem. Phys. 2021, 23, 13842

Received 10th April 2021,

Accepted 3rd June 2021

DOI: $10.1039 / \mathrm{d} 1 \mathrm{cp} 01571 \mathrm{k}$

rsc.li/pccp

\section{The pnictogen bond: a quantitative molecular orbital picture $\dagger$}

\author{
Lucas de Azevedo Santos, (D) ab Trevor A. Hamlin, (ID a Teodorico C. Ramalho (D) bc \\ and F. Matthias Bickelhaupt (D) *ad
}

\begin{abstract}
We have analyzed the structure and stability of archetypal pnictogen-bonded model complexes $D_{3} P n \cdots A^{-}$ $(\mathrm{Pn}=\mathrm{N}, \mathrm{P}, \mathrm{As}, \mathrm{Sb} ; \mathrm{D}, \mathrm{A}=\mathrm{F}, \mathrm{Cl}, \mathrm{Br}$ ) using state-of-the-art relativistic density functional calculations at the ZORA-M06/QZ4P level. We have accomplished two tasks: (i) to compute accurate trends in pnictogen-bond strength based on a set of consistent data; and (ii) to rationalize these trends in terms of detailed analyses of the bonding mechanism based on quantitative Kohn-Sham molecular orbital (KS-MO) theory in combination with a canonical energy decomposition analysis (EDA) and Voronoi deformation density (VDD) analyses of the charge distribution. We have found that pnictogen bonds have a significant covalent character stemming from strong HOMO-LUMO interactions between the lone pair of $A^{-}$and $\sigma^{\star}$ of $D_{3} P n$. As such, the underlying mechanism of the pnictogen bond is similar to that of hydrogen, halogen, and chalcogen bonds.
\end{abstract}

\section{Introduction}

The term pnictogen for the elements of the nitrogen group (group 15) was first proposed by van Arkel in the early 1950s. ${ }^{1}$ Its etymology derives from the Ancient Greek root $\pi \nu$ i ("choke") and is a reference to the Dutch and German names for nitrogen, stikstof and Stickstoff, respectively, which literally mean "suffocation substance". The trivalent pnictogen atom of a Lewis-acidic pnictogen-bond donor $\mathrm{D}_{3} \mathrm{Pn}$ (Pn = group 15 atom) can engage in an intermolecular interaction, coined a pnictogen bond, with a Lewis-basic pnictogen-bond acceptor $\mathrm{A}^{-}{ }^{2}$ One of the first indications of Pn bonding appeared from stacked distibines and dibismuthines in crystal structures ${ }^{3 a}$ and from intramolecular $\mathrm{N} \cdots \mathrm{P}$ contacts in hypervalent phosphorus compounds. $^{3 b}$ Later, a weak $\mathrm{P}$...P interaction was identified via through-space coupling by NMR of phosphanyl-orthocarbaboranes. $^{3 c-e}$ Since then, Pn bonding has flourished and emerged as a tool for coordination chemistry ${ }^{4}$ and catalysis. ${ }^{5}$ The nature of pnictogen bonds (similar to that of chalcogen and

\footnotetext{
${ }^{a}$ Department of Theoretical Chemistry, Amsterdam Institute for Molecular and Life Sciences (AIMMS), Amsterdam Center for Multiscale Modeling (ACMM),

Vrije Universiteit Amsterdam, De Boelelaan 1083, 1081 HV Amsterdam, The Netherlands. E-mail: f.m.bickelhaupt@vu.nl

${ }^{b}$ Department of Chemistry, Institute of Natural Sciences, Universidade Federal de Lavras, 37200-900, Lavras, MG, Brazil

${ }^{c}$ Center for Basic and Applied Research, University Hradec Kralove, Hradec Kralove, Czech Republic

${ }^{d}$ Institute for Molecules and Materials, Radboud University Nijmegen, Heyendaalseweg 135, 6525 AJ Nijmegen, The Netherlands

$\dagger$ Electronic supplementary information (ESI) available: Schematic FMOs, schematic DFT FMOs, and energies and Cartesian coordinates for all stationary points. See DOI: 10.1039/d1cp01571k
}

halogen bonds) is in general considered predominantly electrostatic, ${ }^{6}$ although the bonding mechanism of weak interactions is still under debate. ${ }^{2 b, 7,8}$

In this study, we have computationally analyzed a range of pnictogen-bonded $\mathrm{D}_{3} \mathrm{Pn} \cdots \mathrm{A}^{-}$complexes $(\mathrm{Pn}=\mathrm{N}, \mathrm{P}, \mathrm{As}, \mathrm{Sb} ; \mathrm{D}$, $\mathrm{A}=\mathrm{F}, \mathrm{Cl}, \mathrm{Br}$; see Scheme 1), using relativistic density functional theory (DFT) at the ZORA-M06/QZ4P level. One purpose of our work is to provide a set of consistent structural and energy data from which reliable trends can be inferred for a wide range of model systems. From these data, we have constructed a unified framework to rationalize the nature of pnictogen bonds, chalcogen bonds, halogen bonds, and hydrogen bonds, by studying the associated electronic structure and bonding mechanism. ${ }^{8}$

To this end, the pnictogen atom (Pn), the substituent (D), or the pnictogen bond accepting Lewis base $\left(\mathrm{A}^{-}\right)$are systematically varied to assess how the geometries and energies of our model complexes $\mathrm{D}_{3} \mathrm{Pn} \cdots \mathrm{A}^{-}$are affected. Activation strain analyses ${ }^{9}$ are performed on the formation of the pnictogen-bond complexes to understand the origin of the computed trends. As part of these analyses, the underlying bonding mechanism is elucidated in

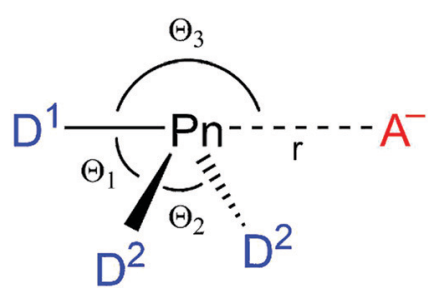

Scheme 1 Pnictogen-bonded $D_{3} P n \cdots A^{-}$model complexes $(P n=N, P$, As, $\mathrm{Sb} ; \mathrm{D}, \mathrm{A}=\mathrm{F}, \mathrm{Cl}, \mathrm{Br}$ ). 
the context of Kohn-Sham molecular orbital (MO) theory in combination with a matching energy decomposition analysis (EDA) as implemented in the Amsterdam Density Functional (ADF) program. ${ }^{10,11}$ Our analyses along the entire reaction profile for each of the pnictogen-bond complexation reactions demonstrate that pnictogen bonds are not at all purely electrostatic phenomena. Instead, they are, to a substantial extent, covalent in nature, very similar to chalcogen bonds, halogen bonds, and hydrogen bonds.

\section{Theoretical methods}

\section{Computational details}

All calculations were carried out using the Amsterdam Density Functional (ADF) 2017.103 program. $^{11}$ The equilibrium geometries and energies of pnictogen-bonded complexes were computed at the DFT level using the meta-hybrid functional M06. ${ }^{12}$ A large uncontracted relativistically optimized QZ4P Slater type orbital (STO) basis set containing diffuse functions was used. The QZ4P all-electron basis set, ${ }^{13}$ no frozen-core approximation, is of quadruple- $\zeta$ quality for all atoms and has been augmented with the following sets of polarization and diffuse functions: two $3 \mathrm{~d}$ and two $4 \mathrm{f}$ on nitrogen and fluorine, three $3 \mathrm{~d}$ and two $4 \mathrm{f}$ on phosphorus and chlorine, two $4 \mathrm{~d}$ and three $4 \mathrm{f}$ on arsenic and bromine, and one $5 \mathrm{~d}$ and three $4 \mathrm{f}$ on antimony and iodine. The molecular density was fitted by the systematically improvable Zlm fitting scheme. Scalar relativistic effects were accounted for using the zerothorder regular approximation (ZORA) Hamiltonian. ${ }^{14}$

\section{Analysis of the bonding mechanism}

Insight into the bonding mechanism is obtained through activation strain analyses of the various pnictogen bond formation reactions. These complexation reactions are computationally modeled by decreasing the distance between $\mathrm{A}^{-}$and the Pn atom of the $\mathrm{D}_{3} \mathrm{Pn}$ fragment, allowing the system to geometrically relax at each point. The $\mathrm{D}_{3} \mathrm{Pn} \cdots \mathrm{A}^{-}$distance is increased, starting from the equilibrium geometry in the pnictogen-bonded complex $\left(r_{\mathrm{Pn} \cdots \mathrm{A}}\right)$, to a value of $5.300 \AA$ A. Thus, each analysis starts from an optimized $\mathrm{D}_{3} \mathrm{Pn} \cdots \mathrm{A}^{-}$complex, which is then transformed into the $\mathrm{D}_{3} \mathrm{Pn}$ molecule and a halide at a relatively large distance.

These complexation reactions are analyzed using the activation strain model. The activation strain model of chemical reactivity ${ }^{9}$ is a fragment-based approach to understand the energy profile of a chemical process in terms of the original reactants. Thus, the potential energy surface $\Delta E(\zeta)$ is decomposed along the reaction coordinate $\zeta$ (or just at one point along $\zeta$ ) into the strain energy $\Delta E_{\text {strain }}(\zeta)$, which is associated with the geometrical deformation of the individual reactants as the process takes place, plus the actual interaction energy $\Delta E_{\text {int }}(\zeta)$ between the deformed reactants [eqn (1)].

$$
\Delta E(\zeta)=\Delta E_{\text {strain }}(\zeta)+\Delta E_{\text {int }}(\zeta)
$$

In the equilibrium geometry, that is, for $\zeta=\zeta_{\text {eq }}$, this yields an expression for the bond energy $\Delta E\left(\zeta_{\text {eq }}\right)=\Delta E_{\text {strain }}+\Delta E_{\text {int }}$.
The PyFrag program was used to facilitate the analyses along the reaction coordinate $\zeta$ of the bond formation processes. ${ }^{15}$ The interaction energy $\Delta E_{\text {int }}(\zeta)$ between the deformed reactants is further analyzed in the conceptual framework provided by the quantitative Kohn-Sham MO model. ${ }^{10}$ To this end, it is decomposed into three physically meaningful terms [eqn (2)] using a quantitative energy decomposition analysis (EDA) as implemented in ADF. ${ }^{10,11}$

$$
\Delta E_{\text {int }}(\zeta)=\Delta V_{\text {elstat }}(\zeta)+\Delta E_{\text {Pauli }}(\zeta)+\Delta E_{\text {oi }}(\zeta)
$$

The usually attractive term $\Delta V_{\text {elstat }}$ corresponds to the classical Coulomb interaction between the unperturbed charge distributions of the deformed reactants and has four components [eqn (3)]: (i) the electrostatic repulsion between the electron densities of fragments 1 and 2, $\Delta V_{\text {elstat }, \rho_{1} \rho_{2}}$; (ii) the electrostatic attraction between the nucleus of fragment 1 and the electron density of fragment 2, $\Delta V_{\text {elstat, } \mathrm{n}_{1} \rho_{2}}$; (iii) the electrostatic attraction between the electron density of fragment 1 and the nucleus of fragment 2, $\Delta V_{\text {elstat, } \rho_{1} \mathrm{n}_{2}}$; and (iv) the electrostatic repulsion between the nuclei of fragments 1 and 2, $\Delta V_{\text {elstat, } \mathrm{n}_{1} \mathrm{n}_{2}}$.

$$
\begin{gathered}
\Delta V_{\text {elstat }}(\zeta)=\Delta V_{\text {elstat }, \rho_{1} \rho_{2}}(\zeta)+\Delta V_{\text {elstat }, \mathrm{n}_{1} \rho_{2}}(\zeta)+\Delta V_{\text {elstat }, \rho_{1} \mathrm{n}_{2}}(\zeta)+ \\
\Delta V_{\text {elstat }, \mathrm{n}_{1} \mathrm{n}_{2}}(\zeta)
\end{gathered}
$$

The Pauli repulsion energy ( $\left.\Delta E_{\text {Pauli }}\right)$ comprises the destabilizing interactions between occupied orbitals of one reactant and those of another reactant and is responsible for steric repulsion. The orbital-interaction energy $\left(\Delta E_{\mathrm{oi}}\right)$ accounts for charge transfer, that is, the interaction between occupied orbitals of one fragment and unoccupied orbitals of the other fragment, including the interactions of the highest occupied and lowest unoccupied MOs (HOMO-LUMO), and polarization, that is, empty-occupied orbital mixing on one fragment, due to the presence of another fragment.

The electron density distribution is analyzed using the Voronoi deformation density (VDD) method for computing atomic charges. ${ }^{16}$ The VDD atomic charge on atom $\mathrm{X}$ in a molecule $\left(Q_{\mathrm{X}}^{\mathrm{VDD}}\right)$ is computed as the (numerical) integral of the deformation density in the volume of the Voronoi cell of atom X [eqn (4)]. The Voronoi cell of atom X is defined as the compartment of space bounded by the bond midplanes on and perpendicular to all bond axes between nucleus $\mathrm{X}$ and its neighboring nuclei.

$$
Q_{\mathrm{X}}^{\mathrm{VDD}}-\int_{\text {Voronoi cell of } \mathrm{X}}\left[\rho(r)-\rho_{\text {promolecule }}(r)\right] \mathrm{d} r
$$

Here, the deformation density is the difference between $\rho(r)$, i.e., the electron density of the overall molecule or complex, and $\rho_{\text {promolecule }}(r)=\sum_{\mathrm{Y}} \rho_{\mathrm{Y}}(\mathrm{r})$, i.e., the superposition of spherical average-of-configuration atomic densities $\rho_{\mathrm{Y}}(r)$ of each atom $Y$ in the fictitious promolecule without chemical interactions, in which all atoms are considered neutral. The interpretation of the VDD charge $Q_{\mathrm{Pn}}^{\mathrm{VDD}}$ is rather straightforward and transparent: instead of measuring the amount of charge associated with a particular atom $\mathrm{Pn}, Q_{\mathrm{Pn}}^{\mathrm{VDD}}$ directly monitors how much charge flows out of $\left(Q_{\mathrm{Pn}}^{\mathrm{VDD}}>0\right)$ or into $\left(Q_{\mathrm{Pn}}^{\mathrm{VDD}}<0\right)$ the Voronoi cell of atom Pn due to chemical interactions. 
The VDD scheme can also be used to directly compute how much charge flows into or out of an atomic Voronoi cell $\mathrm{X}$ in an overall complex (e.g., $\left[\mathrm{D}_{3} \mathrm{Pn} \cdots \mathrm{A}\right]^{-}$) relative to two (poly)atomic molecular fragments (e.g., $\mathrm{D}_{3} \mathrm{Pn}$ and $\mathrm{A}^{-}$), instead of spherical atoms, as shown in eqn (5).

$$
Q_{\mathrm{X}}^{\mathrm{VDD}}-\int_{\substack{\text { Voronoi } \\ \text { cell } \mathrm{X} \text { in the complex }}}\left[\rho_{\text {complex }}(r)-\rho_{\text {fragment } 1}(r)-\rho_{\text {fragment } 2}\right] \mathrm{d} r
$$

$\Delta Q_{\mathrm{X}}^{\mathrm{VDD}}$ is a measure of how the atomic charge of atom $\mathrm{X}$ changes due to the bonding between the fragments. In this work, eqn (5) is used to compute the flow of electrons from the halide $\mathrm{A}^{-}$to the pnictogen-bond donating molecule $\mathrm{D}_{3} \mathrm{Pn}$ (see $\Delta Q_{\mathrm{D}_{3} \mathrm{Pn}}^{\mathrm{VDD}}$ in Tables 1 and 3 ).

\section{Results and discussion}

\section{Pnictogen bond strength and structure}

Table 1 summarizes the results of our ZORA-M06/QZ4P calculations for a representative selection of nitrogen-, phosphorus-, and antimony-bonded model complexes $\mathrm{D}_{3} \mathrm{Pn} \cdots \mathrm{A}^{-}$, covering $\mathrm{D}, \mathrm{A}=$ $\mathrm{F}, \mathrm{Cl}$, and $\mathrm{Br}$ (for the complete dataset see Tables S1 and S2, ESI $\dagger$ ). These model reactions go with a single-well potential energy surface (PES), that is, there is no energy barrier separating the reactants from their resulting product. In the cases where $\mathrm{D} \neq \mathrm{A}$, $C_{\mathrm{S}}$ symmetric complexes with $\mathrm{D}^{1}-\mathrm{Pn}$ bond lengths different from the Pn $\cdots \mathrm{A}^{-}$bond and with bond angles $\Theta_{1} \neq \Theta_{2}$ are formed.
For the cases where $\mathrm{D}=\mathrm{A}, C_{2 \mathrm{v}}$ symmetric complexes with equal bond distances $r_{\mathrm{D}^{1}-\mathrm{Pn}}=r_{\mathrm{Pn} \cdots \mathrm{A}}$ are formed (see Table 1).

The pnictogen bonds $\mathrm{D}_{3} \mathrm{Pn} \cdot \mathrm{A}^{-}$become stronger and longer upon descending group 15 in the periodic table, going from $\mathrm{N}$ to $\mathrm{Sb}$. The pnictogen bonds become weaker and longer as the accepting halide $\left(\mathrm{A}^{-}\right)$goes down group 17 , from $\mathrm{F}^{-}$to $\mathrm{Br}^{-}$. The elongation of the bonds descending the periodic table originates from the increase in the effective size of the atoms involved. In the case of the antimony-bonded complexes $\mathrm{Br}_{3} \mathrm{Sb} \cdots \mathrm{A}^{-}$, for example, $\Delta E$ weakens from a value of $-78 \mathrm{kcal} \mathrm{mol}{ }^{-1}$ for $\mathrm{A}^{-}=\mathrm{F}^{-}$to $-38 \mathrm{kcal} \mathrm{mol}^{-1}$ for $\mathrm{A}^{-}=\mathrm{Br}^{-}$ (see Table 1). The associated $\mathrm{Sb} \cdot \mathrm{A}^{-}$bond elongates from around $2.0 \AA$ for $\mathrm{A}^{-}=\mathrm{F}^{-}$to around $2.8 \AA$ for $\mathrm{A}^{-}=\mathrm{Br}^{-}$. From $\mathrm{A}^{-}=\mathrm{F}^{-}$to $\mathrm{Br}^{-}$, the nitrogen bond in $\mathrm{Br}_{3} \mathrm{~N} \cdots \mathrm{A}^{-}$weakens from a value of $-30 \mathrm{kcal} \mathrm{mol}^{-1}$ to $-7 \mathrm{kcal} \mathrm{mol}^{-1}$. The associated $\mathrm{N} \cdots \mathrm{A}^{-}$bond elongates from a value of around $1.4 \AA$ for $\mathrm{A}^{-}=\mathrm{F}^{-}$ to around $2.3 \AA$ for $\mathrm{A}^{-}=\mathrm{Br}^{-}$. The reason behind the trends in stability will be discussed later.

The strengths of the heavier pnictogen bonds $\mathrm{D}_{3} \mathrm{Pn} \cdots \mathrm{A}^{-}$are minimally affected upon variation of the substituent $\mathrm{D}$. For example, along the series from $\mathrm{F}_{3} \mathrm{Sb} \cdots \mathrm{F}^{-}$to $\mathrm{Br}_{3} \mathrm{Sb} \cdots \mathrm{F}^{-}$, the bond strength varies only from -72.0 to $-77.7 \mathrm{kcal} \mathrm{mol}^{-1}$, the antimony bond distance $r_{\mathrm{Pn} \cdots \mathrm{A}}$ decreases slightly from 2.037 to $2.014 \AA$, and the stretch $\Delta r_{\mathrm{D}^{1}-\mathrm{Pn}}$ upon bond formation increases from 0.144 to $0.332 \AA$. The nitrogen bonds $\mathrm{D}_{3} \mathrm{~N} \cdots \mathrm{A}^{-}$ behave differently and become significantly stronger and shorter as $\mathrm{D}$ is varied from $\mathrm{F}$ to $\mathrm{Br}$ (see Table 1). For example, along the series from $\mathrm{F}_{3} \mathrm{~N} \cdots \mathrm{F}^{-}$to $\mathrm{Br}_{3} \mathrm{~N} \cdots \mathrm{F}^{-}$, the nitrogen bond strengthens from a $\Delta E$ value of -11.8 to $-30.2 \mathrm{kcal} \mathrm{mol}^{-1}$, the

Table 1 Activation strain analyses (in $\mathrm{kcal} \mathrm{mol}^{-1}$ ) of a representative set of $\mathrm{D}_{3} \mathrm{Pn} \cdots \mathrm{A}^{-}$at the equilibrium geometries (in $\AA$, deg.) ${ }^{a}$

\begin{tabular}{|c|c|c|c|c|c|c|c|c|c|}
\hline $\mathrm{D}_{3} \mathrm{Pn} \cdots \mathrm{A}^{-}$ & $\Delta E$ & $\Delta E_{\text {strain }}$ & $\Delta E_{\text {int }}$ & $\Delta Q_{\mathrm{D}_{3} \mathrm{Pn}}^{\mathrm{VDD}}$ & $r_{\mathrm{Pn} \cdots \mathrm{A}}$ & $\Delta r_{\mathrm{D}^{1-P n}}$ & $\Delta r_{\mathrm{D}^{2}-\mathrm{Pn}}$ & $\Theta_{3}$ & $\Delta \Theta_{1}$ \\
\hline $\mathrm{F}_{3} \mathrm{~N} \cdots \mathrm{F}^{-}$ & -11.8 & 32.5 & -44.3 & -0.30 & 1.859 & 0.503 & -0.017 & 170.3 & -8.9 \\
\hline $\mathrm{F}_{3} \mathrm{~N} \cdots \mathrm{Cl}^{-}$ & -3.5 & 0.8 & -4.3 & -0.01 & 3.239 & 0.048 & -0.009 & 168.3 & -1.5 \\
\hline $\mathrm{F}_{3} \mathrm{~N} \cdots \mathrm{Br}^{-}$ & -2.9 & 0.5 & -3.5 & 0.00 & 3.484 & 0.040 & -0.008 & 166.8 & -1.2 \\
\hline $\mathrm{Cl}_{3} \mathrm{~N} \cdot \mathrm{F}^{-}$ & -30.4 & 55.7 & -86.1 & -0.65 & 1.416 & 1.490 & 0.001 & 170.7 & -25.7 \\
\hline $\mathrm{Cl}_{3} \mathrm{~N} \cdots \mathrm{Cl}^{-}$ & -5.6 & 22.9 & -28.5 & -0.36 & 2.328 & 0.575 & 0.004 & 146.6 & -7.8 \\
\hline $\mathrm{Cl}_{3} \mathrm{~N} \cdots \mathrm{Br}^{-}$ & -6.2 & 3.5 & -9.7 & -0.18 & 2.920 & 0.149 & 0.024 & 145.6 & -2.8 \\
\hline $\mathrm{Br}_{3} \mathrm{~N} \cdots \mathrm{F}^{-}$ & -30.2 & 53.2 & -83.3 & -0.67 & 1.411 & 1.417 & 0.022 & 165.7 & -24.0 \\
\hline $\mathrm{Br}_{3} \mathrm{~N} \cdots \mathrm{Cl}^{-}$ & -8.0 & 2.0 & -10.0 & -0.18 & 2.813 & 0.111 & 0.026 & 149.4 & -2.8 \\
\hline $\mathrm{Br}_{3} \mathrm{~N} \cdots \mathrm{Br}^{-}$ & -7.0 & 17.2 & -24.2 & -0.44 & 2.322 & 0.416 & 0.066 & 127.2 & -3.1 \\
\hline $\mathrm{F}_{3} \mathrm{P} \cdots \mathrm{F}^{-}$ & -48.9 & 17.4 & -66.4 & -0.35 & 1.753 & 0.189 & 0.044 & 189.4 & -10.6 \\
\hline $\mathrm{F}_{3} \mathrm{P} \cdots \mathrm{Cl}^{-}$ & -16.0 & 4.4 & -20.4 & -0.12 & 2.700 & 0.083 & 0.016 & 183.4 & -5.6 \\
\hline $\mathrm{F}_{3} \mathrm{P} \cdots \mathrm{Br}^{-}$ & -12.9 & 3.0 & -15.9 & -0.09 & 2.982 & 0.067 & 0.012 & 181.6 & -4.6 \\
\hline $\mathrm{Cl}_{3} \mathrm{P} \cdots \mathrm{F}^{-}$ & -67.4 & 31.8 & -99.3 & -0.52 & 1.649 & 0.572 & 0.048 & 181.4 & -11.8 \\
\hline $\mathrm{Cl}_{3} \mathrm{P} \cdots \mathrm{Cl}^{-}$ & -25.5 & 14.4 & -39.8 & -0.31 & 2.370 & 0.315 & 0.034 & 174.6 & -8.7 \\
\hline $\mathrm{Cl}_{3} \mathrm{P} \cdots \mathrm{Br}^{-}$ & -20.5 & 10.7 & -31.3 & -0.26 & 2.617 & 0.263 & 0.030 & 172.9 & -7.6 \\
\hline $\mathrm{Br}_{3} \mathrm{P} \cdots \mathrm{F}^{-}$ & -71.0 & 30.2 & -101.2 & -0.56 & 1.637 & 0.647 & 0.045 & 175.4 & -11.3 \\
\hline $\mathrm{Br}_{3} \mathrm{P} \cdots \mathrm{Cl}^{-}$ & -28.5 & 15.4 & -43.9 & -0.37 & 2.312 & 0.382 & 0.038 & 172.0 & -8.9 \\
\hline $\mathrm{Br}_{3} \mathrm{P} \cdots \mathrm{Br}^{-}$ & -23.4 & 11.9 & -35.3 & -0.32 & 2.550 & 0.323 & 0.034 & 170.6 & -7.9 \\
\hline $\mathrm{F}_{3} \mathrm{Sb} \cdots \mathrm{F}^{-}$ & -72.0 & 8.8 & -80.8 & -0.31 & 2.037 & 0.144 & 0.037 & 193.9 & -8.9 \\
\hline $\mathrm{F}_{3} \mathrm{Sb} \cdots \mathrm{Cl}^{-}$ & -38.9 & 5.8 & -44.7 & -0.21 & 2.643 & 0.112 & 0.030 & 188.3 & -7.3 \\
\hline $\mathrm{F}_{3} \mathrm{Sb} \cdots \mathrm{Br}^{-}$ & -33.6 & 5.0 & -38.7 & -0.19 & 2.840 & 0.103 & 0.028 & 186.7 & -6.8 \\
\hline $\mathrm{Cl}_{3} \mathrm{Sb} \cdots \mathrm{F}^{-}$ & -77.1 & 12.3 & -89.4 & -0.38 & 2.017 & 0.301 & 0.051 & 183.7 & -7.6 \\
\hline $\mathrm{Cl}_{3} \mathrm{Sb} \cdots \mathrm{Cl}^{-}$ & -42.7 & 8.9 & -51.7 & -0.28 & 2.592 & 0.244 & 0.045 & 178.4 & -6.5 \\
\hline $\mathrm{Cl}_{3} \mathrm{Sb} \cdots \mathrm{Br}^{-}$ & -37.3 & 8.0 & -45.3 & -0.27 & 2.780 & 0.229 & 0.043 & 177.0 & -6.1 \\
\hline $\mathrm{Br}_{3} \mathrm{Sb} \cdots \mathrm{F}^{-}$ & -77.7 & 11.5 & -89.2 & -0.41 & 2.014 & 0.332 & 0.049 & 181.2 & -7.2 \\
\hline $\mathrm{Br}_{3} \mathrm{Sb} \cdots \mathrm{Cl}^{-}$ & -43.5 & 8.5 & -52.0 & -0.31 & 2.580 & 0.272 & 0.046 & 175.6 & -6.1 \\
\hline $\mathrm{Br}_{3} \mathrm{Sb} \cdots \mathrm{Br}^{-}$ & -38.1 & 7.7 & -45.8 & -0.30 & 2.766 & 0.256 & 0.045 & 174.2 & -5.8 \\
\hline
\end{tabular}

${ }^{a}$ Computed at the ZORA-M06/QZ4P level. For a full set of data, see Tables S1 and S2 in the ESI. 
nitrogen bond distance $r_{\mathrm{Pn} \cdots \mathrm{A}}$ decreases in value from 1.859 to $1.411 \AA$, and the stretch $\Delta r_{\mathrm{D}^{1}-\mathrm{Pn}}$ significantly increases from 0.503 to $1.417 \AA$. A comprehensive analysis of the origin of these trends is provided in the following.

\section{Bond analyses with the variation of Pn}

The pnictogen bond $\mathrm{D}_{3} \mathrm{Pn} \cdots \mathrm{A}^{-}$strength $\Delta E$ increases as $\mathrm{Pn}$ varies along $\mathrm{N}, \mathrm{P}, \mathrm{As}$, and $\mathrm{Sb}$ when the donating atom (D) and the accepting halide $\left(\mathrm{A}^{-}\right)$remain unchanged and the trend in $\Delta E$ is mainly set by the interaction energy $\Delta E_{\text {int }}$. For example, from $\mathrm{F}_{3} \mathrm{~N} \cdots \mathrm{F}^{-}$to $\mathrm{F}_{3} \mathrm{Sb} \cdots \mathrm{F}^{-}, \Delta E$ is strengthened from a value of -11.8 to $-72.0 \mathrm{kcal} \mathrm{mol}^{-1}$ and $\Delta E_{\text {int }}$ is strengthened from a value of -44.3 to $-80.8 \mathrm{kcal} \mathrm{mol}^{-1}$ (see Table 1 ). The trend in $\Delta E$ is reinforced by the strain energy ( $\left.\Delta E_{\text {strain }}\right)$, which becomes less destabilizing from 32.5 to $8.8 \mathrm{kcal} \mathrm{mol}^{-1}$ along the same series. We extend our analysis to the entire reaction coordinate $\zeta$, projected onto the stretch in the $\mathrm{D}^{1}-\mathrm{Pn}$ bond, $\Delta r_{\mathrm{D}^{1-P n}}$, that occurs as the pnictogen-bond accepting $\mathrm{A}^{-}$atom approaches the $\mathrm{D}_{3} \mathrm{Pn}$ molecule (see the Theoretical methods section). The activation strain and energy decomposition diagrams (ASD and EDD) for a representative example series, namely $\mathrm{F}_{3} \mathrm{~N} \cdots \mathrm{F}^{-}$to $\mathrm{F}_{3} \mathrm{Sb} \cdots \mathrm{F}^{-}$, are given in Fig. 1 (for the complete dataset, see Tables S1 and S2 in the ESI $\dagger$ ). Notably, the trend in bond energy $\Delta E(\zeta)$ is in fact determined by $\Delta E_{\text {int }}(\zeta)$, which strengthens when going from $\mathrm{Pn}=\mathrm{N}$ to $\mathrm{Sb}$ (Fig. 1, left), whereas the $\Delta E_{\text {strain }}(\zeta)$ curves are relatively similar. In fact, only in the equilibrium geometries, the strain term $\Delta E_{\text {strain }}\left(\zeta_{\text {eq }}\right)$ become less destabilizing from $\mathrm{Pn}=\mathrm{N}$ to $\mathrm{Sb}$. The reason is that as the interaction curve becomes steeper along the series, it pulls the equilibrium geometry [which results from the balance between $\Delta E_{\text {strain }}(\zeta)$ and $\left.\Delta E_{\text {int }}(\zeta)\right]$ to an earlier stage along the reaction coordinate, at which the system is less distorted (i.e., a less expanded $\mathrm{F}^{1}-\mathrm{Pn}$ bond in the $\mathrm{F}_{3} \mathrm{Pn}$ fragment) and thus less strained, as reflected by $\Delta E_{\text {strain }}\left(\zeta_{\text {eq }}\right)$ (see Table 1 ).

To understand the trends in $\Delta E_{\text {int }}(\zeta)$, we further decomposed $\Delta E_{\text {int }}$ into the individual energy components (Fig. 1, right; for a full set of data, see Fig. S2 in the ESI $\dagger)$. The strengthening of $\Delta E_{\text {int }}(\zeta)$ and, consequently, the increasing stabilization of $\mathrm{D}_{3} \mathrm{Pn} \cdots \mathrm{A}^{-}$as Pn varies along $\mathrm{N}, \mathrm{P}, \mathrm{As}$, and $\mathrm{Sb}$ is caused by the rising electronegativity difference across the D-Pn bonds as Pn descends in the periodic table. Firstly, this causes the Pn atom to become increasingly positive along $\mathrm{N}, \mathrm{P}, \mathrm{As}$, and $\mathrm{Sb}$ (see the VDD atomic charges in Table 2), resulting in the $\Delta V_{\text {elstat }}(\zeta)$ curves being the least stabilizing for $\mathrm{Pn}=\mathrm{N}$ and the most stabilizing for $\mathrm{Pn}=\mathrm{Sb}$. For example, the VDD atomic charge on $\mathrm{Pn}$ in $\mathrm{F}_{3} \mathrm{~N}, \mathrm{~F}_{3} \mathrm{P}$, $\mathrm{F}_{3} \mathrm{As}$, and $\mathrm{F}_{3} \mathrm{Sb}$ amounts to $+0.21,+0.33$, +0.51 , and +0.57 a.u., respectively. Secondly, this causes, among other effects that will be explained later, the $\sigma^{*} \mathrm{D}-\mathrm{Pn}$ antibonding $5 \mathrm{a}^{\prime}$ acceptor orbital to have higher amplitude on Pn (see Fig. 2), resulting in stronger HOMO-LUMO overlap and thus more stabilizing orbital interactions. These features are also observed for chalcogen bonds $\mathrm{D}_{2} \mathrm{Ch} \cdots \mathrm{A}^{-}$, halogen bonds $\mathrm{DX} \cdots \mathrm{A}^{-}$, and hydrogen bonds $\mathrm{DH} \cdots \mathrm{A}^{-}$, which makes them similar to pnictogen bonds. ${ }^{8}$

Our analyses reveal that the pnictogen bonding mechanism is not purely electrostatic but, instead, has a relatively large covalent component $\left(\Delta E_{\mathrm{oi}}\right)$, stemming mainly from the HOMOLUMO interaction between the occupied halide $n \mathrm{p}_{\mathrm{y}}$ atomic orbital (AO) and the $\sigma^{*} \mathrm{D}-\mathrm{Pn}$ antibonding $5 \mathrm{a}^{\prime}$ acceptor orbital (see Fig. 2). For the pnictogen-bonded complexes, the orbitalinteraction term ranges from $34 \%$ for $\mathrm{F}_{3} \mathrm{Sb} \cdots \mathrm{F}^{-}$to as much as $65 \%$ for $\mathrm{Br}_{3} \mathrm{~N} \cdots \mathrm{Cl}^{-}$of the total bonding interactions $\left(\Delta E_{\mathrm{oi}}+\right.$ $\Delta V_{\text {elstat }}$; see Table 3$)$, and the orbital interaction curves $\Delta E_{\mathrm{oi}}(\zeta)$ become more stabilizing from $\mathrm{Pn}=\mathrm{N}$ to $\mathrm{Sb}$ (Fig. 1, right). The stronger orbital interaction for the heavier pnictogens is the result of the larger LUMO-HOMO overlap (i.e. $\left\langle 5 \mathrm{a}^{\prime} \mid n \mathrm{p}_{\mathrm{y}}\right\rangle$; see Fig. 2 for the MO diagram that depicts the $n \mathrm{p}_{\mathrm{y}}$ orbital of $\mathrm{A}^{-}$ oriented towards the $\mathrm{D}^{1}-\mathrm{Pn}$ bond of the $\mathrm{D}_{3} \mathrm{Pn}$ fragment) as $\mathrm{Pn}$ becomes more electropositive. For example, in the $\mathrm{Cl}_{3} \mathrm{Pn} \cdots \mathrm{Cl}^{-}$ series, $\left\langle 5 \mathrm{a}^{\prime} \mid n \mathrm{p}_{\mathrm{y}}\right\rangle$ increases from 0.11 to 0.20 to 0.22 along $\mathrm{Pn}=$ $\mathrm{N}, \mathrm{P}$, and $\mathrm{Sb}$ in the equilibrium geometry (see Table 3). The associated charge transfer from $\mathrm{A}^{-}$to $\mathrm{D}_{3} \mathrm{Pn}$ is reflected by the VDD charge of the $\mathrm{D}_{3} \mathrm{Pn}$ fragment in the complex,
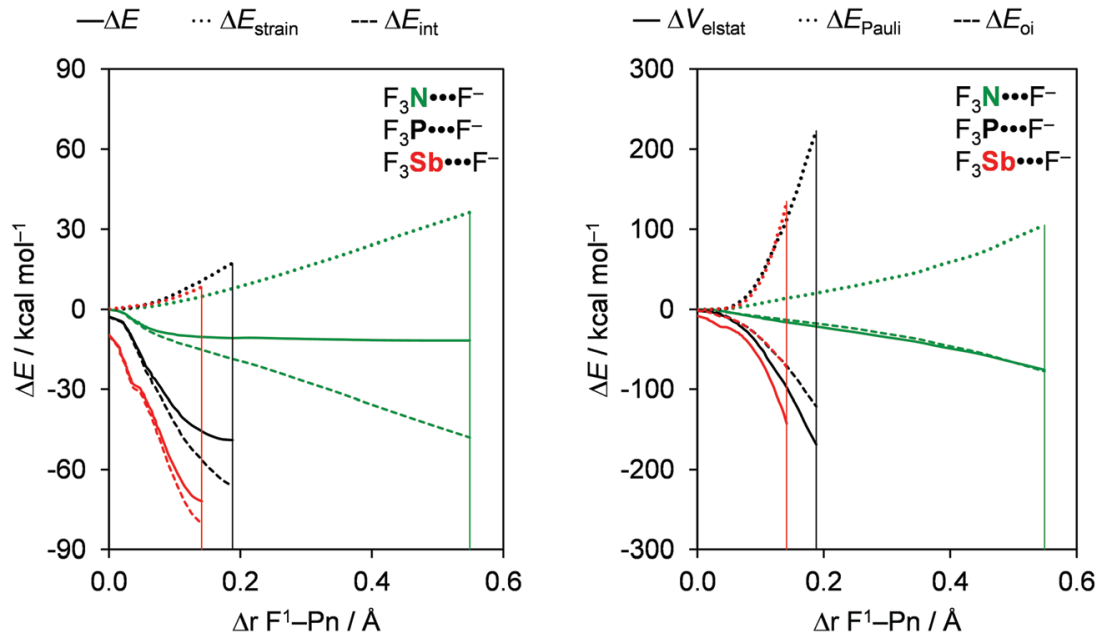

Fig. 1 Activation strain (left panel) and energy decomposition (right panel) analyses of a representative set of $\mathrm{F}_{3} P n \ldots \mathrm{F}^{-}$pnictogen-bonded complexes (green, $\mathrm{Pn}=\mathrm{N}$; black, $\mathrm{Pn}=\mathrm{P}$; red, $\mathrm{Pn}=\mathrm{Sb}$ ). The vertical lines indicate the position of the stationary points. For a full set of data, see Fig. S2 in the ESI. $\dagger$ 
Table 2 Bond lengths (in Å), bond angle (in deg.), VDD charge (in a.u.), orbital energies (in eV) and the homolytic bond dissociation energy without ZPE (in kcal mol${ }^{-1}$ ) of isolated $D_{3} P n$ fragments ${ }^{a}$

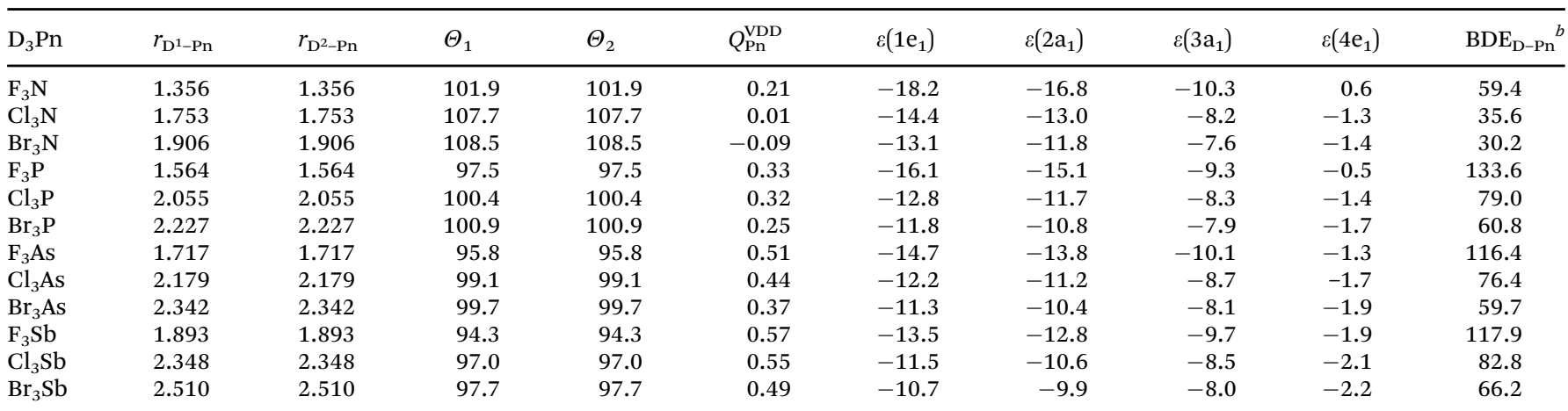

${ }^{a}$ Computed at the ZORA-M06/QZ4P level. ${ }^{b}$ Energy for the reaction $\mathrm{D}_{3} \mathrm{Pn} \rightarrow \mathrm{D}_{2} \mathrm{Pn} \bullet+\mathrm{D}^{\bullet}$.

a)

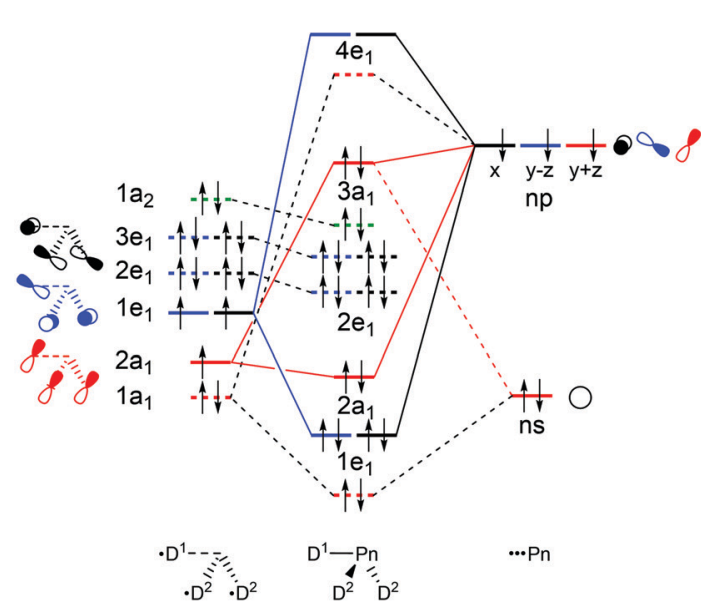

b)

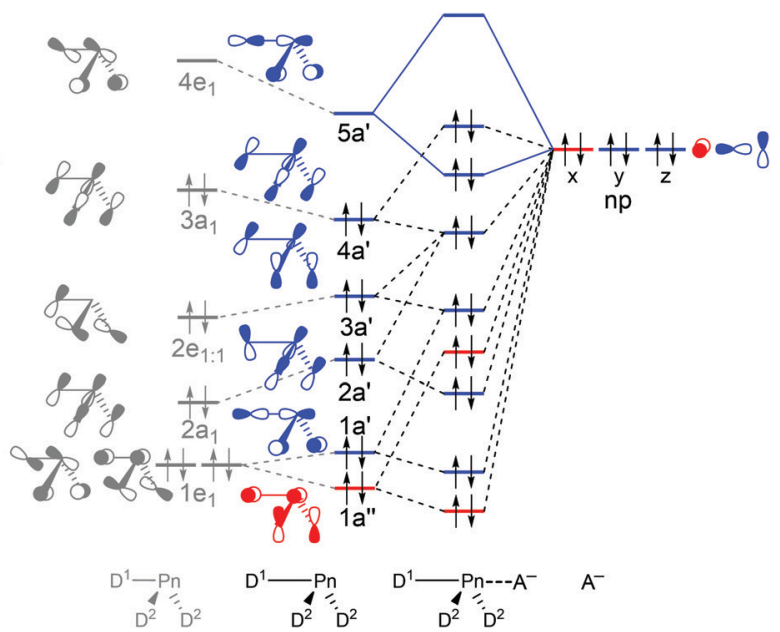

Fig. 2 Schematic molecular orbital diagram for (a) isolated $D_{3} P n$ fragments with $C_{3 v}$ symmetry (red: $a_{1} ;$ green: $a_{2} ;$ blue: $e_{1: 1 ;} ;$ black: $\left.e_{1: 2}\right)$ and $(b) D_{3} P n \ldots A^{-}$ complexes. The first column in (b) refers to the isolated $D_{3} P n$ fragment and the second column refers to the $D_{3} P n$ fragment deformed to its $C_{s}$ symmetric geometry in the complex (blue: $a^{\prime}$; red: $a^{\prime \prime}$ ), in which one D-Pn bond has been elongated. See Fig. S1 in the ESI† for computed 3D isosurfaces of the orbitals.

$\Delta Q_{\mathrm{D}_{3} \mathrm{Pn}}^{\mathrm{VDD}}$, which is negative (see Table 1). Thus, $\mathrm{D}_{3} \mathrm{Pn}$ gains charge from $\mathrm{A}^{-}$upon complexation, for all $\mathrm{D}_{3} \mathrm{Pn} \cdots \mathrm{A}^{-}$complexes. For example, $\Delta Q_{\mathrm{D}_{3} \mathrm{Pn}}^{\mathrm{VDD}}$ is -0.30 a.u. for $\mathrm{F}_{3} \mathrm{~N} \cdots \mathrm{F}^{-}$and -0.31 a.u. for $\mathrm{F}_{3} \mathrm{Sb} \cdots \mathrm{F}^{-}$. The HOMO-LUMO charge transfer nature of the pnictogen bond is also reflected by the $3 \mathrm{D}$ plots of the deformation densities associated with pnictogen-bond formation in $\mathrm{F}_{3} \mathrm{P} \cdots \mathrm{F}^{-}$ and $\mathrm{F}_{3} \mathrm{Sb} \cdots \mathrm{F}^{-}$(see Fig. 3). Note the charge depletion in the region of the HOMO on the Lewis base $\mathrm{F}^{-}$(and within the Pn $\cdots \mathrm{F}^{-}$bond due to Pauli repulsion ${ }^{10 a}$ ) and the charge accumulation in the region of the LUMO on $\mathrm{D}_{3} \mathrm{Pn}$.

The $\Delta E_{\mathrm{oi}}(\zeta)$ curves become more stabilizing if one goes from nitrogen to the heavier pnictogen bonds, but, interestingly, the orbital interaction $\Delta E_{\mathrm{oi}}\left(\zeta_{\mathrm{eq}}\right)$ at the stationary point of the complex turns out to be comparable in magnitude for all pnictogens (see Table 3). The reason is the significantly more pronounced stretch in the $\mathrm{F}^{1}-\mathrm{Pn}$ bond for $\mathrm{Pn}=\mathrm{N}$ than for the heavier pnictogens. This phenomenon causes $\Delta E_{\mathrm{oi}}\left(\zeta_{\mathrm{eq}}\right)$ for nitrogen to occur at a later point at which the intrinsically less stabilizing $\Delta E_{\mathrm{oi}}(\zeta)$ curve has achieved a more stabilizing value that, as mentioned above, is comparable to the value of the other pnictigen bonds that do not feature this strong $\mathrm{F}^{1}-\mathrm{Pn}$ bond stretch.

The reason that $\mathrm{F}^{1}-\mathrm{Pn}$ streches more for $\mathrm{Pn}=\mathrm{N}$ than for the heavier pnictogens is its lower polarity and thus weaker bond strength (see Table 2) which translates into less strain when it streches upon complexation with the Lewis base (see Fig. 1). Thus, as the $\mathrm{F}^{1}-\mathrm{Pn}$ bond in the $\mathrm{F}_{3} \mathrm{Pn} \cdots \mathrm{F}^{-}$complexes expands the most, the $\sigma^{*} \mathrm{D}-\mathrm{Pn}$ antibonding $5 \mathrm{a}^{\prime}$ acceptor orbital drops significantly in energy and, due to a smaller HOMO-LUMO gap, enters into a more stabilizing donor-acceptor orbital interaction $\Delta E_{\mathrm{oi}}\left(\zeta_{\mathrm{eq}}\right)$ (see Fig. $2 \mathrm{~b}$ ). This effect can be observed in Fig. 4a, which shows the energies of the $\sigma^{*} \mathrm{~F}-\mathrm{Pn}$ antibonding $5 \mathrm{a}^{\prime}$ acceptor orbitals, as well as the VDD atomic charge on Pn in the $\mathrm{F}_{3} \mathrm{Pn}$ fragments, along the reaction coordinate. The $\mathrm{F}^{1}-\mathrm{Pn}$ bond in the $\mathrm{F}_{3} \mathrm{Pn} \cdots \mathrm{F}^{-}$complexes expands less from $\mathrm{Pn}=\mathrm{N}$ to $\mathrm{Sb}$ and leads to a smaller stabilization of the $\sigma^{*} \mathrm{D}-\mathrm{Pn}$ 
Table 3 Energy decomposition analyses (in $\mathrm{kcal} \mathrm{mol}^{-1}$ ) of a representative set of $\mathrm{D}_{3} \mathrm{Pn} \cdots \mathrm{A}^{-}$at the equilibrium geometries ${ }^{\mathrm{a}}$

\begin{tabular}{|c|c|c|c|c|c|c|c|c|c|c|}
\hline $\mathrm{D}_{3} \mathrm{Pn} \cdots \mathrm{A}^{-}$ & $\Delta E_{\mathrm{int}}$ & $\Delta V_{\text {elstat }}$ & $\Delta E_{\text {Pauli }}$ & $\Delta E_{\mathrm{oi}}$ & $\varepsilon\left(5 \mathrm{a}^{\prime}\right)$ & $\left\langle 5 \mathrm{a}^{\prime} \mid n \mathrm{p}_{\mathrm{y}}\right\rangle$ & $\left\langle 4 \mathrm{a}^{\prime} \mid n \mathrm{p}_{\mathrm{y}}\right\rangle$ & Pop $_{5 a^{\prime}}$ & Pop $_{n \text { py }}$ & $\Delta Q_{\mathrm{D}_{3} \mathrm{Pn}}^{\mathrm{VDD}}$ \\
\hline $\mathrm{F}_{3} \mathrm{~N} \cdots \mathrm{F}^{-}$ & -44.3 & -66.9 & 89.6 & -67.0 & -5.1 & 0.12 & 0.05 & 0.40 & 1.68 & -0.30 \\
\hline $\mathrm{F}_{3} \mathrm{~N} \cdots \mathrm{Cl}^{-}$ & -4.3 & -5.8 & 4.5 & -3.1 & -0.2 & 0.10 & 0.05 & 0.02 & 1.99 & -0.01 \\
\hline $\mathrm{F}_{3} \mathrm{~N} \cdots \mathrm{Br}^{-}$ & -3.5 & -4.7 & 3.5 & -2.3 & -0.1 & 0.10 & 0.04 & 0.02 & 2.00 & 0.00 \\
\hline $\mathrm{Cl}_{3} \mathrm{~N} \cdots \mathrm{F}^{-}$ & -86.1 & -208.3 & 431.6 & -309.5 & -6.5 & 0.13 & 0.08 & 1.24 & 1.34 & -0.65 \\
\hline $\mathrm{Cl}_{3} \mathrm{~N} \cdots \mathrm{Cl}^{-}$ & -28.5 & -41.8 & 69.2 & -55.9 & -5.2 & 0.11 & 0.06 & 0.54 & 1.59 & -0.36 \\
\hline $\mathrm{Cl}_{3} \mathrm{~N} \cdots \mathrm{Br}^{-}$ & -9.7 & -11.9 & 18.8 & -16.7 & -3.7 & 0.09 & 0.03 & 0.26 & 1.75 & -0.18 \\
\hline $\mathrm{Br}_{3} \mathrm{~N} \cdots \mathrm{F}^{-}$ & -83.3 & -204.1 & 439.6 & -318.8 & -6.0 & 0.12 & 0.07 & 1.25 & 1.38 & -0.67 \\
\hline $\mathrm{Br}_{3} \mathrm{~N} \cdots \mathrm{Cl}^{-}$ & -10.0 & -10.3 & 19.2 & -18.9 & -3.6 & 0.08 & 0.04 & 0.23 & 1.86 & -0.18 \\
\hline $\mathrm{Br}_{3} \mathrm{~N} \cdots \mathrm{Br}^{-}$ & -24.2 & -51.1 & 95.0 & -68.1 & -4.6 & 0.12 & 0.08 & 0.67 & 1.60 & -0.44 \\
\hline $\mathrm{F}_{3} \mathrm{P} \cdots \mathrm{F}^{-}$ & -66.4 & -167.7 & 221.7 & -120.3 & -2.1 & 0.15 & 0.19 & 0.28 & 1.75 & -0.35 \\
\hline $\mathrm{F}_{3} \mathrm{P} \cdots \mathrm{Cl}^{-}$ & -20.4 & -40.4 & 46.0 & -25.9 & -1.2 & 0.22 & 0.17 & 0.17 & 1.87 & -0.12 \\
\hline $\mathrm{F}_{3} \mathrm{P} \cdots \mathrm{Br}^{-}$ & -15.9 & -29.1 & 30.7 & -17.4 & -1.1 & 0.25 & 0.16 & 0.18 & 1.81 & -0.09 \\
\hline $\mathrm{Cl}_{3} \mathrm{P} \cdots \mathrm{F}^{-}$ & -99.3 & -222.6 & 312.1 & -188.7 & -4.1 & 0.16 & 0.13 & 0.48 & 1.70 & -0.52 \\
\hline $\mathrm{Cl}_{3} \mathrm{P} \cdots \mathrm{Cl}^{-}$ & -39.8 & -84.8 & 119.2 & -74.2 & -3.1 & 0.20 & 0.12 & 0.40 & 1.73 & -0.31 \\
\hline $\mathrm{Cl}_{3} \mathrm{P} \cdots \mathrm{Br}^{-}$ & -31.3 & -64.2 & 86.5 & -53.6 & -2.9 & 0.20 & 0.08 & 0.36 & 1.75 & -0.26 \\
\hline $\mathrm{Br}_{3} \mathrm{P} \cdots \mathrm{F}^{-}$ & -101.2 & -228.4 & 331.2 & -204.1 & -4.2 & 0.15 & 0.12 & 0.53 & 1.69 & -0.56 \\
\hline $\mathrm{Br}_{3} \mathrm{P} \cdots \mathrm{Cl}^{-}$ & -43.9 & -95.9 & 141.9 & -89.8 & -3.4 & 0.19 & 0.13 & 0.45 & 1.72 & -0.37 \\
\hline $\mathrm{Br}_{3} \mathrm{P} \cdots \mathrm{Br}^{-}$ & -35.3 & -73.7 & 104.8 & -66.5 & -3.2 & 0.20 & 0.12 & 0.42 & 1.72 & -0.32 \\
\hline $\mathrm{F}_{3} \mathrm{Sb} \cdots \mathrm{F}^{-}$ & -80.8 & -148.9 & 143.6 & -75.5 & -3.0 & 0.16 & 0.15 & 0.20 & 1.82 & -0.31 \\
\hline $\mathrm{F}_{3} \mathrm{Sb} \cdots \mathrm{Cl}^{-}$ & -44.7 & -82.6 & 83.4 & -45.4 & -2.7 & 0.23 & 0.18 & 0.21 & 1.83 & -0.21 \\
\hline $\mathrm{F}_{3} \mathrm{Sb} \cdots \mathrm{Br}^{-}$ & -38.7 & -70.7 & 70.9 & -38.9 & -2.7 & 0.24 & 0.18 & 0.21 & 1.84 & -0.19 \\
\hline $\mathrm{Cl}_{3} \mathrm{Sb} \cdots \mathrm{F}^{-}$ & -89.4 & -158.0 & 161.0 & -92.4 & -3.4 & 0.16 & 0.11 & 0.26 & 1.79 & -0.38 \\
\hline $\mathrm{Cl}_{3} \mathrm{Sb} \cdots \mathrm{Cl}^{-}$ & -51.7 & -93.3 & 100.9 & -59.2 & -3.2 & 0.22 & 0.11 & 0.28 & 1.80 & -0.28 \\
\hline $\mathrm{Cl}_{3} \mathrm{Sb} \cdots \mathrm{Br}^{-}$ & -45.3 & -81.1 & 87.3 & -51.5 & -3.1 & 0.23 & 0.10 & 0.28 & 1.82 & -0.27 \\
\hline $\mathrm{Br}_{3} \mathrm{Sb} \cdots \mathrm{F}^{-}$ & -89.2 & -157.4 & 166.1 & -97.9 & -3.4 & 0.16 & 0.10 & 0.28 & 1.79 & -0.41 \\
\hline $\mathrm{Br}_{3} \mathrm{Sb} \cdots \mathrm{Cl}^{-}$ & -52.0 & -95.2 & 106.8 & -63.5 & -3.2 & 0.21 & 0.11 & 0.29 & 1.81 & -0.31 \\
\hline $\mathrm{Br}_{3} \mathrm{Sb} \cdots \mathrm{Br}^{-}$ & -45.8 & -83.2 & 92.7 & -55.3 & -3.2 & 0.22 & 0.11 & 0.30 & 1.81 & -0.30 \\
\hline
\end{tabular}

${ }^{a}$ Computed at the ZORA-M06/QZ4P level; $\varepsilon\left(5 \mathrm{a}^{\prime}\right)=5 \mathrm{a}^{\prime}$ orbital energy of the prepared $\mathrm{D}_{3}$ Pn fragment (in eV); $\langle\Phi \mid n \mathrm{p}\rangle=$ overlap between the $\Phi$ orbital of the $\mathrm{D}_{3} \mathrm{Pn}$ fragment (see Fig. 2) and one of the $n \mathrm{p}$ orbitals of the halide $\mathrm{A}^{-}$; Pop = Gross population (in electrons) of the indicated orbital. For a full set of data, see Table S2 in the ESI.

a)

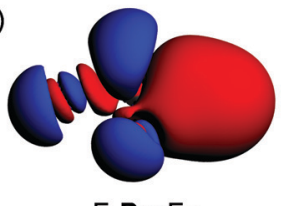
$\mathrm{F}_{3} \mathrm{P} \cdot \bullet \mathrm{F}^{-}$

b)

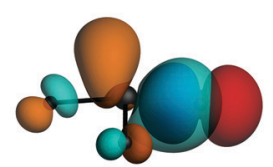

$\mathrm{F}_{3} \mathrm{P} \cdots \mathrm{F}^{-}$ c)

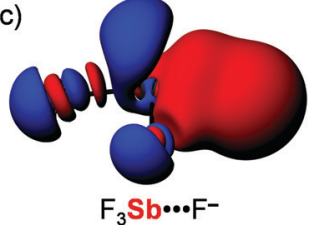

d)

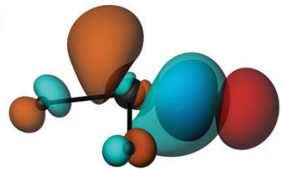

$\mathrm{F}_{3} \mathrm{Sb} \cdots \mathrm{F}^{-}$

Fig. 3 Deformation density $\left(\Delta \rho(r)=\rho_{\left[\mathrm{D} 3 P_{n} \cdots \mathrm{A}^{-}\right]}(r)-\rho_{\mathrm{D} 3 \mathrm{Pn}}(r)-\rho_{\mathrm{A}^{-}}(r)\right.$ : red $=$ depletion; blue = accumulation) plot (a and $\mathrm{c}$ ) and HOMO-LUMO interaction ( $b$ and $d$ ) for a representative series of $\mathrm{D}_{3} \mathrm{Pn} \ldots \mathrm{A}^{-}$pnictogen bonds.

antibonding $5 \mathrm{a}^{\prime}$ acceptor orbital and the decrease in the HOMO-LUMO gap becomes smaller from $\mathrm{Pn}=\mathrm{N}$ to $\mathrm{Sb}$, resulting in less stabilization by orbital interactions. For example, for Pn = $\mathrm{Sb}$, the energy of the $\sigma^{*} \mathrm{~F}-\mathrm{Sb}$ antibonding $5 \mathrm{a}^{\prime}$ acceptor orbital is up to $-3.0 \mathrm{eV}$ in $\mathrm{F}_{3} \mathrm{Sb}$ at the equilibrium geometry of the $\mathrm{F}_{3} \mathrm{Sb} \cdots \mathrm{F}^{-}$complex. Due to the weaker $\mathrm{F}-\mathrm{N}$ bond compared to $\mathrm{F}-\mathrm{Sb}$ (e.g. $\mathrm{BDE}_{\mathrm{F}-\mathrm{N}}=59.4 \mathrm{kcal} \mathrm{mol}{ }^{-1}$ and $\mathrm{BDE}_{\mathrm{F}-\mathrm{Sb}}=$ $117.9 \mathrm{kcal} \mathrm{mol}^{-1}$; see Table 2), the $\mathrm{F}^{1}-\mathrm{N}$ bond expands to a

higher extent and the $\sigma^{*} \mathrm{~F}-\mathrm{N}$ antibonding $5 \mathrm{a}^{\prime}$ acceptor orbital quickly drops to a value of $-5.1 \mathrm{eV}$.

Nevertheless, the nitrogen-bonded complexes remain the weakest as the high stabilization of the $\sigma^{*} \mathrm{~F}-\mathrm{N}$ antibonding $5 \mathrm{a}^{\prime}$ acceptor orbital is counteracted by its poor orbital overlap with the $n \mathrm{p}_{\mathrm{y}}$ donor orbital due to the absence of radial nodes in and, thus, the very compact nature of the nitrogen $2 p$ valence AOs (see Table 3 ).

In addition, note that, as the $\mathrm{F}^{1}-\mathrm{Pn}$ bond in the $\mathrm{F}_{3} \mathrm{Pn} \cdots \mathrm{F}^{-}$ complexes expands, the pnictogen atom in the $\mathrm{D}_{3} \mathrm{Pn}$ fragment becomes more positive (Fig. 4a), resulting in a more stabilizing electrostatic $\Delta V_{\text {elstat }}\left(\zeta_{\text {eq }}\right)$ (see Table 3). However, the significant expansion of the $\mathrm{F}^{1}-\mathrm{N}$ bond is not enough to make the highly electronegative $\mathrm{N}$ atom as positive as the heavier pnictogens, making the nitrogen-bonded complexes also the least stabilized by electrostatic attraction.

\section{Bond analyses with the variation of $\mathrm{A}^{-}$}

Our analyses show that the pnictogen bonds $\mathrm{D}_{3} \mathrm{Pn} \cdots \mathrm{A}^{-}$become weaker as the Lewis basicity of the $\mathrm{A}^{-}$halide decreases from $\mathrm{F}^{-}$ to $\mathrm{Br}^{-} \cdot{ }^{17}$ Again, this is equivalent to what was found for chalcogen bonds $\mathrm{D}_{2} \mathrm{Ch} \cdots \mathrm{A}^{-}$, halogen bonds $\mathrm{DX} \cdots \mathrm{A}^{-}$, and hydrogen bonds $\mathrm{DH} \cdots \mathrm{A}^{-} .{ }^{8}$ As aforementioned, pnictogen bonds have both an electrostatic component $\left(\Delta V_{\text {elstat }}\right)$ and a covalent component $\left(\Delta E_{\mathrm{oi}}\right)$ stemming mainly from the HOMO-LUMO interaction between the occupied halide $n \mathrm{p}$ atomic orbital (AO) and the $\sigma^{*} \mathrm{D}-\mathrm{Pn}$ antibonding $5 \mathrm{a}^{\prime}$ acceptor orbital, shown schematically in Fig. 2. The electron-donating capacity of the halides is reduced as the halide $n \mathrm{p}$ AOs become 
$-\varepsilon\left(5 a^{\prime}\right) \quad---Q_{P n}^{V D D}$
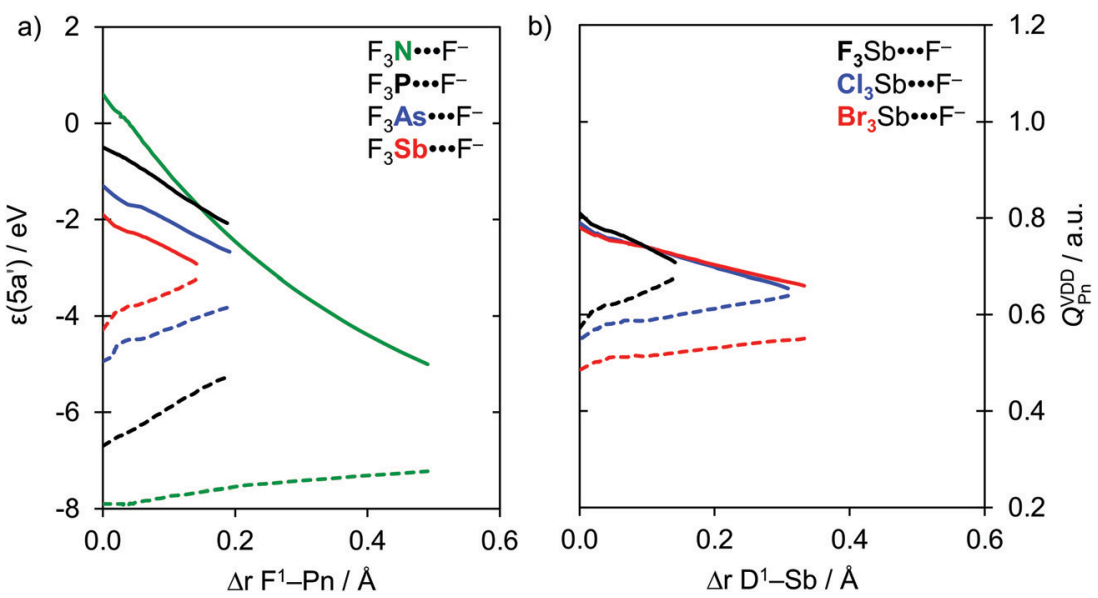

Fig. 4 Energy of the $5 a^{\prime}$ orbital (in eV) and the VDD charge on the Pn atom (in a.u.) in the neutral fragment $D_{3} P n$ projected onto (a) the $F^{1}-P n$ bond stretch (green, $\mathrm{Pn}=\mathrm{N}$; black, $\mathrm{Pn}=\mathrm{P} ;$ blue, $\mathrm{Pn}=\mathrm{As}$; red, $\mathrm{Pn}=\mathrm{Sb}$ ) and $(\mathrm{b})$ the $\mathrm{D}^{1}-\mathrm{Sb}$ bond stretch (black, $\mathrm{D}=\mathrm{F} ; \mathrm{blue}, \mathrm{D}=\mathrm{Cl} ; \mathrm{red}, \mathrm{D}=\mathrm{Br}$ ).

more diffuse and lower in energy from $\mathrm{A}^{-}=\mathrm{F}^{-}$to $\mathrm{Br}^{-}$, thus weakening $\Delta E_{\mathrm{oi}}{ }^{8,17 b}$ This will also result in longer bonds and weaker electrostatic attraction. As a result, the interaction energy $\left(\Delta E_{\text {int }}\right)$ and, thus, the net pnictogen-bond strength $\Delta E$ become less stabilizing along $\mathrm{A}^{-}=\mathrm{F}^{-}$to $\mathrm{Br}^{-}$(see Table 1 and Table S1 in the ESI $\dagger$ ).
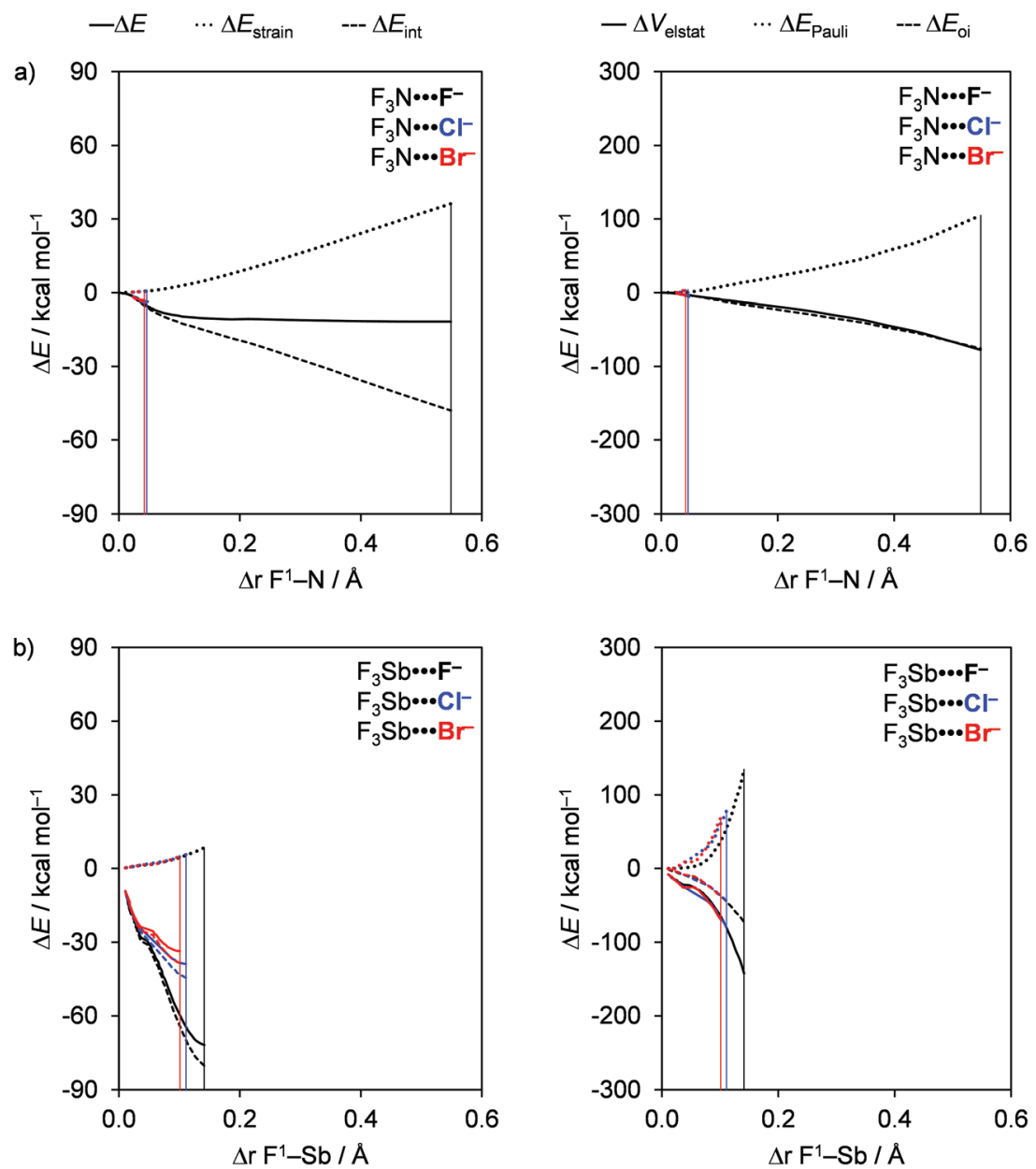

Fig. 5 Activation strain (left panel) and energy decomposition (right panel) analyses of (a) $\mathrm{F}_{3} \mathrm{~N} \cdots \mathrm{A}^{-}$and $(\mathrm{b}) \mathrm{F}_{3} \mathrm{Sb} \cdots \mathrm{A}^{-}\left(\mathrm{black}, \mathrm{A}^{-}=\mathrm{F}^{-} ;\right.$blue, $\mathrm{A}^{-}=\mathrm{Cl}^{-}$; red, $\mathrm{A}^{-}=\mathrm{Br}^{-}$). The vertical lines indicate the position of the stationary points. 
Activation strain analyses reveal that the trend $\mathrm{A}^{-}=\mathrm{F}^{-}$to $\mathrm{Br}^{-}$in the total energy $\Delta E(\zeta)$ is directly determined by the trend in the corresponding interaction energies, that is, $\Delta E_{\text {int }}(\zeta)$ weakens from $\mathrm{A}^{-}=\mathrm{F}^{-}$to $\mathrm{Br}^{-}$. This is nicely seen in the left diagrams in Fig. 5, which shows the formation of the pnictogen bonds $\mathrm{D}_{3} \mathrm{Pn} \cdots \mathrm{A}^{-}$, with $\mathrm{A}^{-}=\mathrm{F}^{-}, \mathrm{Cl}^{-}$, and $\mathrm{Br}^{-}$, for a representative series of $\mathrm{F}_{3} \mathrm{~N}$ and $\mathrm{F}_{3} \mathrm{Sb}$ molecules. Note that the $\Delta E_{\text {strain }}$ curves coincide (because they stem from the same molecule with the same $\mathrm{F}-\mathrm{N}$ bond being stretched as the complexation reaction progresses) and, thus, do not affect the trends in $\Delta E(\zeta)$. For the nitrogen bonds involving the Lewis bases $\mathrm{A}^{-}=\mathrm{Cl}^{-}$and $\mathrm{Br}^{-}$, the bond strength is particularly weak because the interaction is too weak to significantly stretch the $\mathrm{D}^{1}-\mathrm{N}$ bonds. Consequently, the $\mathrm{D}_{3} \mathrm{~N}$ fragment achieves a much weaker electron-accepting capacity in this less distorted equilibrium geometry and so the eventual interaction and bond energy become relatively weak (see Fig. 5a).

The trend in $\Delta E_{\text {int }}(\zeta)$ is again dictated by the bonding components $\Delta V_{\text {elstat }}$ and $\Delta E_{\mathrm{oi}}$. This can be seen in the right panel of Fig. 5 , which shows that both $\Delta V_{\text {elstat }}(\zeta)$ and $\Delta E_{\mathrm{oi}}(\zeta)$ become more stabilizing from $\mathrm{A}^{-}=\mathrm{F}^{-}$to $\mathrm{Br}^{-}$. The key to understand these trends is of course related to the factors that enhance the strength of the bonding components and, thus, $\Delta E_{\text {int }}$ : firstly, an approaching halide $\mathrm{A}^{-}$with a higher lying HOMO and, secondly, a weak D-Pn bond that is easily stretched resulting in a $\sigma^{*} \mathrm{D}-\mathrm{Pn}$ antibonding $5 \mathrm{a}^{\prime}$ acceptor orbital that quickly drops in energy as the $\mathrm{D}^{1}-\mathrm{Pn}$ bond elongates (see Fig. 4). These factors are the driving force for $\mathrm{D}^{1}-\mathrm{Pn}$ stretching in $\mathrm{D}_{3} \mathrm{Pn} \cdots \mathrm{A}^{-}$since they generate stronger orbital interactions and, therefore, stronger pnictogen bonds. For $\mathrm{F}_{3} \mathrm{~N} \cdots \mathrm{A}^{-}$, the $5 \mathrm{a}^{\prime}$ acceptor orbital energy in the equilibrium geometry of the complex adopts significantly lower values for weaker Lewis bases $\left(\mathrm{A}^{-}=\mathrm{Cl}^{-}\right.$or $\left.\mathrm{Br}^{-}\right)$than for $\mathrm{A}^{-}=\mathrm{F}^{-}$(i.e., $-5.1 \mathrm{eV}$ for $\mathrm{A}^{-}=\mathrm{F}^{-},-0.2 \mathrm{eV}$ for $\mathrm{A}^{-}=\mathrm{Cl}^{-}$, and $-0.1 \mathrm{eV}$ for $\mathrm{A}^{-}=\mathrm{Br}^{-}$; see Table 3). Indeed, $\mathrm{D}^{1}-\mathrm{Pn}$ stretching is most pronounced if this bond in the neutral fragment is weaker (e.g., ca. $59 \mathrm{kcal} \mathrm{mol}^{-1}$ for $\mathrm{F}-\mathrm{N}$, ca. $35 \mathrm{kcal} \mathrm{mol}^{-1}$ for Cl-N, and ca. $30 \mathrm{kcal} \mathrm{mol}^{-1}$ for $\mathrm{Br}-\mathrm{N}$; see Table 2). For example, the $\mathrm{D}^{1}-\mathrm{N}$ stretching in the nitrogen-bonded complexes is longer in $\mathrm{Br}_{3} \mathrm{~N} \cdots \mathrm{F}^{-}$, for which $\Delta r_{\mathrm{D}^{1}-\mathrm{Pn}}$ is $1.4 \AA$, and less pronounced in $\mathrm{F}_{3} \mathrm{~N} \cdots \mathrm{F}^{-}$, for which $\Delta r_{\mathrm{D}^{1}-\mathrm{Pn}}$ is $0.5 \AA$ (see Table 1 ). As a result, the bonding components, $\Delta V_{\text {elstat }}$ and $\Delta E_{\text {oi }}$, become significantly stronger, up to $-300 \mathrm{kcal} \mathrm{mol}{ }^{-1}$, in the $\mathrm{Cl}_{3} \mathrm{~N} \cdots \mathrm{A}^{-}$and the $\mathrm{Br}_{3} \mathrm{~N} \cdots \mathrm{A}^{-}$series. However, the bonding components are significantly weakened
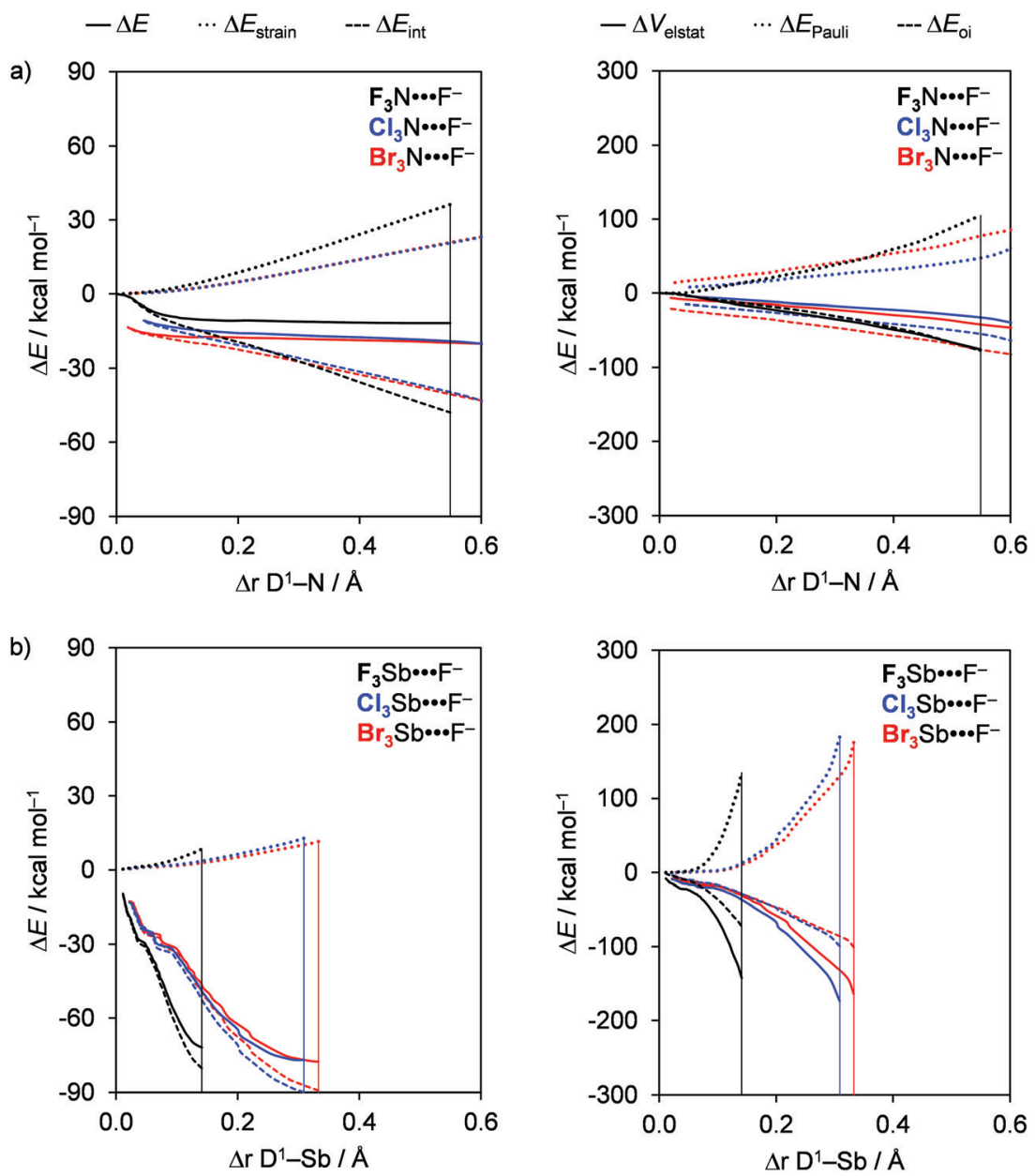

Fig. 6 Activation strain (left panel) and energy decomposition (right panel) analyses of (a) $D_{3} N \cdots F^{-}$and (b) $D_{3} S b \cdots F^{-}$(black, $D=F$; blue, $D=C l$; red, $\mathrm{D}=\mathrm{Br}$ ). The vertical lines indicate the position of the stationary points. 
to $c a$. $-60 \mathrm{kcal} \mathrm{mol}^{-1}$ for weaker Lewis bases, in which case $\Delta r_{\mathrm{D}^{1}-\mathrm{Pn}}$ varies between only 0.04 and $0.6 \AA$ (see Table 1 ).

\section{Bond analyses with the variation of $D$}

The strength of the heavier $\mathrm{D}_{3} \mathrm{Pn} \cdots \mathrm{A}^{-}$pnictogen bonds $(\mathrm{Pn}=\mathrm{P}$, $\mathrm{As}, \mathrm{Sb}$ ) slightly strengthens when the substituent $\mathrm{D}$ varies from $\mathrm{F}$ to $\mathrm{Br}$. Based on the purely electrostatic picture of the $\sigma$-hole model, one might expect just the opposite, that is, a weakening of the pnictogen bond in $\mathrm{D}_{3} \mathrm{Pn} \cdots \mathrm{A}^{-}$as $\mathrm{D}$ varies from $\mathrm{F}$ to $\mathrm{Br}$ due to a decrease in the positive molecular electrostatic potential of the $\sigma$-hole at the Pn atom in the $\mathrm{D}_{3} \mathrm{Pn}$ fragment $\left(V_{\mathrm{S}, \max }\right){ }^{6 a, 18}$ This apparent discrepancy from the $\sigma$-hole model is traced to the trend that D-Pn bonds become weaker along $\mathrm{F}-\mathrm{Pn}, \mathrm{Cl}-\mathrm{Pn}$ and Br-Pn (see Table 2). And, the weaker the D-Pn bonds, the more they elongate in the eventual equilibrium geometry of the corresponding $\mathrm{D}_{3} \mathrm{Pn} \cdots \mathrm{A}^{-}$complex. Therefore, the latter is reached at a later stage along the reaction coordinate $\Delta r_{\mathrm{D}^{1}-\mathrm{Pn}}$. A consequence of this D-Pn bond elongation is a more electropositive Pn atom and a lower energy of the $\sigma^{*} \mathrm{D}-\mathrm{Pn}$ antibonding $5 \mathrm{a}^{\prime}$ acceptor orbital due to a reduction in antibonding character (see Fig. 4b). This situation translates into more stabilizing $\Delta V_{\text {elstat }}(\zeta)$ and $\Delta E_{\mathrm{oi}}(\zeta)$ curves as $\mathrm{D}$ varies from $\mathrm{F}$ to $\mathrm{Cl}$ to $\mathrm{Br}$ (see Fig. 6, right). For the $\mathrm{D}_{3} \mathrm{~N} \cdots \mathrm{A}^{-}$nitrogen bonds, these effects are most pronounced because the $\mathrm{D}-\mathrm{N}$ bonds in $\mathrm{D}_{3} \mathrm{~N}$ are the weakest halogen-pnictogen bonds. Thus, stronger $\mathrm{D}_{3} \mathrm{~N} \cdots \mathrm{A}^{-}$ complexes with a more pronounced $\mathrm{D}-\mathrm{N}$ stretch occur if we go from $\mathrm{F}_{3} \mathrm{~N}$ to $\mathrm{Cl}_{3} \mathrm{~N}$ and $\mathrm{Br}_{3} \mathrm{~N}$.

In the following, we exemplify the above with a few concrete examples. For the heavier pnictogen bonds ( $\mathrm{Pn}=\mathrm{P}, \mathrm{As}, \mathrm{Sb})$, we find that the trend in bond energy curves $\Delta E(\zeta)$ is set by the interaction energy curves $\Delta E_{\text {int }}(\zeta)$, that is, they become less stabilizing along $\mathrm{D}=\mathrm{F}, \mathrm{Cl}$, and $\mathrm{Br}$. However, as the $\mathrm{D}^{1}-\mathrm{Pn}$ bond expands more for $\mathrm{D}=\mathrm{Cl}$ and $\mathrm{Br}$ compared to $\mathrm{D}=\mathrm{F}$, both $\Delta E\left(\zeta_{\mathrm{eq}}\right)$ and $\Delta E_{\text {int }}\left(\zeta_{\text {eq }}\right)$ in the equilibrium geometry are slightly more stabilizing for $\mathrm{D}=\mathrm{Cl}$ and $\mathrm{Br}$. This trend in the interaction energy curves $\Delta E_{\text {int }}(\zeta)$ is a direct consequence of the electrostatic attraction $\Delta V_{\text {elstat }}$ and orbital interactions $\Delta E_{\mathrm{oi}}$. The curves for the bonding components $\Delta V_{\text {elstat }}(\zeta)$ and $\Delta E_{\mathrm{oi}}(\zeta)$ are the most stabilizing for $\mathrm{D}=\mathrm{F}$ because of the larger difference in electronegativity across the D-Pn bonds (vide supra). Nevertheless, the $\mathrm{Cl}-\mathrm{Pn}$ and $\mathrm{Br}-\mathrm{Pn}$ bonds are substantially weaker than the associated $\mathrm{F}-\mathrm{Pn}$ bond (e.g. $\mathrm{BDE}_{\mathrm{F}-\mathrm{Sb}}=117.9 \mathrm{kcal} \mathrm{mol}^{-1}$, $\mathrm{BDE}_{\mathrm{Cl}-\mathrm{Sb}}=82.8 \mathrm{kcal} \mathrm{mol}^{-1}$, and $\mathrm{BDE}_{\mathrm{Br}-\mathrm{Sb}}=66.2 \mathrm{kcal} \mathrm{mol}^{-1}$; see Table 2), and the Cl-Pn and $\mathrm{Br}-\mathrm{Pn}$ bonds expand to a greater degree. Consequently, $\Delta E_{\mathrm{oi}}(\zeta)$ becomes more stabilizing for $\mathrm{D}=$ $\mathrm{Cl}$ and $\mathrm{Br}$ because the $\sigma^{*} \mathrm{D}-\mathrm{Pn}$ antibonding $5 \mathrm{a}^{\prime}$ acceptor orbital is strongly stabilized and can engage in stronger donor-acceptor interactions with the $n$ p-type lone pair HOMO on $\mathrm{A}^{-}$(see Fig. 4b). In parallel, the VDD atomic charge on Pn becomes increasingly more positive as the $\mathrm{D}^{1}-\mathrm{Pn}$ bond expands

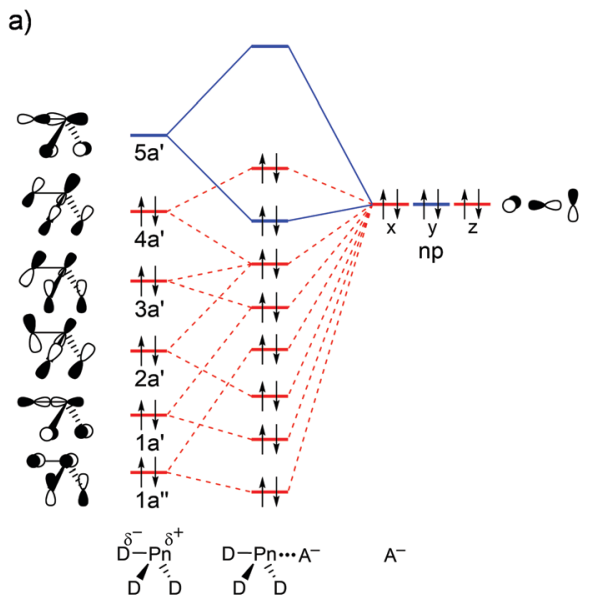

c)

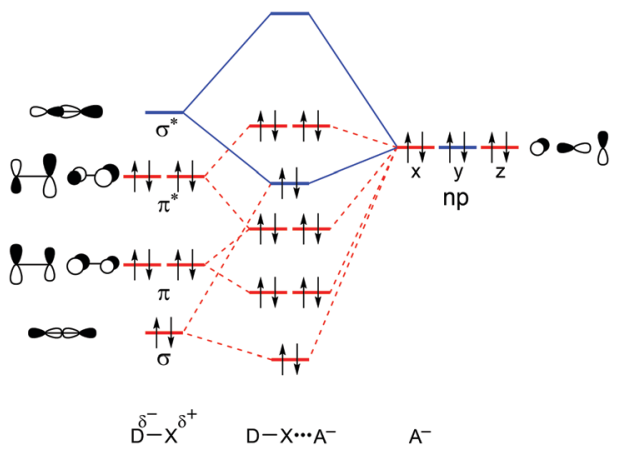

b)

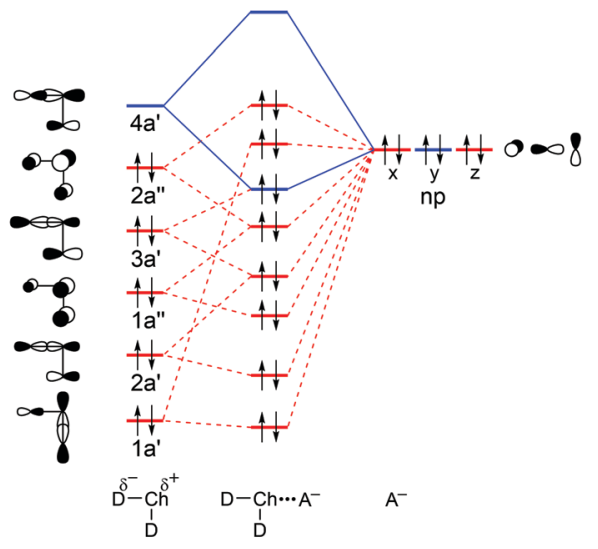

d)

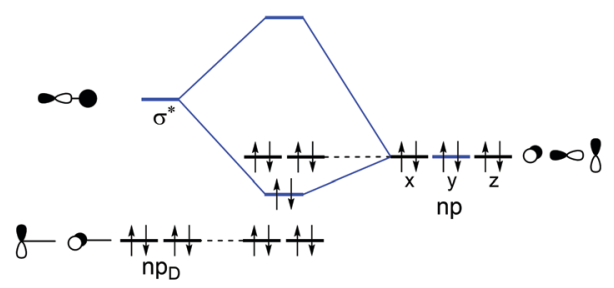

Fig. 7 Generic molecular orbital diagrams for (a) $D_{3} P n \ldots A^{-}$pnictogen bonds, (b) $D_{2} C h \cdots A^{-}$chalcogen bonds, (c) $D X \ldots A^{-}$halogen bonds, and (d) $\mathrm{DH} \cdots \mathrm{A}^{-}$hydrogen bonds. 
(see Fig. $4 \mathrm{~b}$ ), which translates into a more stabilizing $\Delta V_{\text {elstat }}(\zeta)$ for $\mathrm{D}=\mathrm{Cl}$ and $\mathrm{Br}$. This results in the slight strengthening of $\Delta V_{\text {elstat }}\left(\zeta_{\text {eq }}\right)$ and $\Delta E_{\mathrm{oi}}\left(\zeta_{\mathrm{eq}}\right)$, and thus $\Delta E_{\text {int }}\left(\zeta_{\mathrm{eq}}\right)$, in the equilibrium geometry along $\mathrm{D}=\mathrm{F}, \mathrm{Cl}, \mathrm{Br}$.

The $\mathrm{D}_{3} \mathrm{~N} \cdots \mathrm{A}^{-}$complexes, on the other hand, show somewhat deviating behavior as compared to the heavier pnictogen bonding complexes exemplified above. Thus, for the $\mathrm{D}_{3} \mathrm{~N} \cdots \mathrm{A}^{-}$complexes, $\Delta E(\zeta)$ becomes significantly more stabilizing along $\mathrm{D}=\mathrm{F}, \mathrm{Cl}$, and $\mathrm{Br}$ instead of remaining relatively constant. This is because the $\mathrm{D}^{1}-\mathrm{N}$ bonds are all much weaker $\left(\right.$ e.g. $\mathrm{BDE}_{\mathrm{F}-\mathrm{N}}=59.4 \mathrm{kcal} \mathrm{mol}^{-1}$, $\mathrm{BDE}_{\mathrm{Cl}-\mathrm{N}}=35.6 \mathrm{kcal} \mathrm{mol}{ }^{-1}$, and $\mathrm{BDE}_{\mathrm{Br}-\mathrm{N}}=30.2 \mathrm{kcal} \mathrm{mol}^{-1}$; see Table 2), and the stretch $\Delta r_{\mathrm{D}^{1}-\mathrm{Pn}}$ for all nitrogen-bonded complexes is much more pronounced, that is, the complexes occur later in the reaction coordinate. For example, the $\mathrm{D}^{1}-\mathrm{N}$ stretch has variation between 0.5 and $1.4 \AA$ in $\mathrm{D}_{3} \mathrm{~N} \cdots \mathrm{F}^{-}$, whereas the $\mathrm{D}^{1}-\mathrm{Sb}$ stretch varies only between 0.1 and $0.3 \AA$ in $\mathrm{D}_{3} \mathrm{Sb} \cdot \mathrm{F}^{-}$ from $\mathrm{D}=\mathrm{F}$ to $\mathrm{Br}$ (see Table 1 ). As a result, the $\mathrm{D}_{3} \mathrm{~N} \cdots \mathrm{A}^{-}$complexes show more significant strengthening of $\Delta V_{\text {elstat }}\left(\zeta_{\text {eq }}\right)$ and $\Delta E_{\mathrm{oi}}\left(\zeta_{\mathrm{eq}}\right)$ along $\mathrm{D}=\mathrm{F}$ to $\mathrm{Br}$ in the equilibrium geometries, and, therefore, $\mathrm{a}$ significant increase in stability along the same series.

\section{Comparison of pnictogen-, chalcogen-, halogen-, and hydrogen bonds}

Our analyses highlight that pnictogen bonds share strong similarities with the corresponding chalcogen bonds (ChB), halogen bonds (XB), and hydrogen bonds (HB) ${ }^{8}$ We find that these bonds have considerable covalency on top of electrostatic attraction and can range in strength roughly between -3 and $-78 \mathrm{kcal} \mathrm{mol}^{-1}$ (see Fig. 7). The contribution of the covalent component $\Delta E_{\mathrm{oi}}$ to the total bonding components $\left(\Delta V_{\text {elstat }}+\right.$ $\Delta E_{\mathrm{oi}}$ ) is up to $97 \%, 76 \%$, and $65 \%$ for $\mathrm{XB}, \mathrm{ChB}$, and $\mathrm{PnB}$, respectively, whereas it is up to $66 \%$ for $\mathrm{HB}^{8 a, b}$ The same bonding mechanism with a substantial covalent component is also observed for the archetypal $\mathrm{DM} \cdot \mathrm{A}^{-}$alkali- and coinagemetal bonds $(\mathrm{MB})$ that have even more pronounced polarization in the D-M bonds. ${ }^{8 c}$

Our findings consolidate earlier work and support the charge-transfer character of pnictogen bonds by providing a causal bonding mechanism. ${ }^{2 b, 7} \mathrm{PnB}, \mathrm{ChB}$, and $\mathrm{XB}$ are generally stronger than $\mathrm{HB}$ due to more stabilizing orbital interactions (see Table $\mathrm{S} 3$ for bond energies $\Delta E$ of a representative series of $\mathrm{ChB}, \mathrm{XB}$, and $\mathrm{HB}$ ). On the other hand, hydrogen bonds have less destabilizing Pauli repulsion because there is no overlap between the $n p_{D}$ HOMO of the $\mathrm{D}-\mathrm{H}$ fragment and the higherlying occupied np AOs of $\mathrm{A}^{-}$(see Fig. 7). Our analyses also show that $\mathrm{PnB}, \mathrm{ChB}$, and $\mathrm{XB}$, but also $\mathrm{MB}$, have even stronger electrostatic attraction than $\mathrm{HB} .{ }^{8 a, b}$ Note that this cannot be straightforwardly explained by the $\sigma$-hole model, which, based on hydrogen having the highest $V_{\mathrm{S} \text {,max }}$, erroneously suggests that HB should have the stronger electrostatic attraction. ${ }^{6}$

\section{Conclusions}

The pnictogen bonds in $\mathrm{D}_{3} \mathrm{Pn} \cdots \mathrm{A}^{-}$range between 3 and $78 \mathrm{kcal} \mathrm{mol}^{-1}$ in strength, becoming stronger as the pnictogen atom becomes more electropositive, along $\mathrm{Pn}=\mathrm{N}, \mathrm{P}, \mathrm{As}$ and $\mathrm{Sb}$, and also as the halide becomes a stronger Lewis base, along $\mathrm{A}^{-}=\mathrm{Br}^{-}, \mathrm{Cl}^{-}$and $\mathrm{F}^{-}$. The trend upon variation of the substituent along $\mathrm{D}=\mathrm{F}, \mathrm{Cl}, \mathrm{Br}$ is less pronounced, as are all trends for the relatively weak nitrogen bonds. This follows from our bonding analyses based on relativistic density functional theory.

Our activation-strain and quantitative Kohn-Sham MO bonding analyses reveal that the pnictogen bonds in $\mathrm{D}_{3} \mathrm{Pn} \cdots \mathrm{A}^{-}$ have a considerable covalent component $\Delta E_{\mathrm{oi}}$, ranging from $34 \%$ to $65 \%$ of the bonding components $\left(\Delta V_{\text {elstat }}+\Delta E_{\mathrm{oi}}\right)$, stemming from HOMO-LUMO interactions between the $n \mathrm{p}$ type lone pair HOMO on $\mathrm{A}^{-}$and the $\sigma^{*} \mathrm{D}-\mathrm{Pn}$ antibonding LUMO on $\mathrm{D}_{3} \mathrm{Pn}$. The $\mathrm{D}_{3} \mathrm{Pn} \cdots \mathrm{A}^{-}$pnictogen bond becomes stronger as Pn descends in the periodic table along N, P, As and $\mathrm{Sb}$. One reason is the increasing polarization towards Pn of the $\sigma^{*}$ LUMO and the associated increase in the LUMO-HOMO overlap with $\mathrm{A}^{-}$(along $\mathrm{P}, \mathrm{As}$, and $\mathrm{Sb}$ this trend is reinforced by the drop in the $\sigma^{*}$ LUMO energy). Another reason is the higher positive charge on Pn which goes with more stabilizing electrostatic interactions with the Lewis base.

Finally, it appears that the pnictogen bonds in $\mathrm{D}_{3} \mathrm{Pn} \cdots \mathrm{A}^{-}$ are similar in nature to the chalcogen bonds in $\mathrm{D}_{2} \mathrm{Ch} \cdots \mathrm{A}^{-}$, halogen bonds in $\mathrm{DX} \cdots \mathrm{A}^{-}$, and hydrogen bonds in $\mathrm{DH} \cdots \mathrm{A}^{-}$ $(\mathrm{Pn}=\mathrm{N}, \mathrm{P}, \mathrm{As}, \mathrm{Sb}$; Ch = O, S, Se, Te; D, X, A = F, Cl, Br). Our work constitutes a unified picture of all these interactions, which appear to be far from solely electrostatic phenomena. We conclude that the often-used designation of "noncovalent interactions" for these types of bonds is not consistent with their significant covalent nature. Instead of this term, we propose to refer to such bonds as (weak or strong) intermolecular interactions.

\section{Conflicts of interest}

There are no conflicts to declare.

\section{Acknowledgements}

We thank the Brazilian agencies Fundação de Amparo à Pesquisa do Estado de Minas Gerais (FAPEMIG) and Coordenação de Aperfeiçoamento de Pessoal de Nível Superior (CAPES) for the scholarship to LAS, Conselho Nacional de Desenvolvimento Científico e Tecnológico (CNPq) for the fellowship to TCR, and the Netherlands Organization for Scientific Research (NWO) for all the support. This work was carried out on the Dutch national e-infrastructure with the support of SURF Cooperative.

\section{References}

1 G. S. Girolami, J. Chem. Educ., 2009, 86, 1200-1201.

2 (a) S. Scheiner, Acc. Chem. Res., 2013, 46, 280-288; (b) S. Scheiner, Int. J. Quantum Chem., 2013, 113, 1609-1620; (c) J. E. Del Bene, I. Alkorta and J. Elguero, in Noncovalent Forces. Challenges and Advances in 
Computational Chemistry and Physics, ed. S. Scheiner, Springer, Cham, 2015, vol. 19, pp. 191-263; (d) P. R. Joshi and K. Sankaran, J. Mol. Struct, 2020, 1217, 128408; (e) R. Mokrai, J. Barret, D. C. Apperley, A. S. Batsanov, Z. Benkő and D. Heift, Chem. - Eur. J, 2019, 25, 4017-4024. 3 (a) A. J. Ashe III, Adv. Organomet. Chem., 1990, 30, 77-97; (b) F. Carré, C. Chuit, R. J. P. Corriu, P. Monforte, N. K. Nayyar and C. Reyé, J. Organomet. Chem., 1995, 499, 147-154; (c) S. Bauer, S. Tschirschwitz, P. Lönnecke, R. Frank, B. Kirchner, M. L. Clarke and E. Hey-Hawkins, Eur. J. Inorg. Chem., 2009, 12, 2776-2788; (d) S. Zahn, R. Frank, E. HeyHawkins and B. Kirchner, Chem. - Eur. J., 2011, 17, 6034-6038; (e) J. E. Del Bene, I. Alkorta, G. Sanchez-Sanz and J. Elguero, Chem. Phys. Lett., 2011, 512, 184-187.

4 (a) M. S. Taylor, Coord. Chem. Rev., 2020, 413, 213270; (b) K. T. Mahmudov, A. V. Gurbanov, V. A. Aliyeva, G. Resnati and A. J. L. Pombeiro, Coord. Chem. Rev., 2020, 418, 213381; (c) L. M. Lee, M. Tsemperouli, A. I. Poblador-Bahamonde, S. Benz, N. Sakai, K. Sugihara and S. Matile, J. Am. Chem. Soc., 2019, 141, 810-814; (d) K. T. Mahmudov, A. V. Gurbanov, F. I. Guseinov, M. Fátima and C. Guedes da Silva, Coord. Chem. Rev., 2019, 387, 32-46; (e) G. Park and F. P. Gabbaï, Chem. Sci., 2020, 11, 10107-10112; (f) P. Scilabra, G. Terraneo, A. Daolio, A. Baggioli, A. Famulari, C. Leroy, D. L. Bryce and G. Resnati, Cryst. Growth Des., 2020, 20, 916-922.

5 (a) Y. Li, L. Meng, C. Sun and Y. Zeng, J. Phys. Chem. A, 2020, 124, 3815-3824; (b) S. Benz, A. I. Poblador-Bahamonde, N. Low-Ders and S. Matile, Angew. Chem., 2018, 130, 5506-5510 (Angew. Chem., Int. Ed., 2018, 57, 5408-5412); (c) A. Gini, M. Paraja, B. Galmés, C. Besnard, A. I. PobladorBahamonde, N. Sakai, A. Frontera and S. Matile, Chem. Sci., 2020, 11, 7086-7091; (d) M. Paraja, A. Gini, N. Sakai and S. Matile, Chem. - Eur. J., 2020, 26, 1-7.

6 (a) P. Politzer, J. S. Murray and T. Clark, Phys. Chem. Chem. Phys., 2013, 15, 11178-11189; (b) P. Politzer, J. S. Murray and M. C. Concha, J. Mol. Model., 2008, 14, 659-665; (c) P. Politzer, J. S. Murray and T. Clark, J. Phys. Chem. A, 2019, 123, 10123-10130; (d) A. Bauzá, T. J. Mooibroek and A. Frontera, ChemPhysChem, 2015, 16, 2496-2517.

7 (a) R. Shukla and D. Chopra, Phys. Chem. Chem. Phys., 2016, 18, 13820-13829; (b) W. Zierkiewicz, M. Michalczyk, R. Wysokiński and S. Scheiner, J. Mol. Model., 2019, 25, 152; (c) I. Alkorta, J. Elguero and J. E. Del Bene, J. Phys. Chem. A, 2013, 117, 10497-10503; (d) J. E. Del Bene, I. Alkorta and J. Elguero, J. Phys. Chem. A, 2014, 118, 2360-2366; (e) J. E. Del Bene, I. Alkorta and J. Elguero, J. Phys. Chem. A, 2014, 118, 3386-3392.
8 (a) L. P. Wolters and F. M. Bickelhaupt, ChemistryOpen, 2012, 1, 96-105; (b) L. de Azevedo Santos, S. C. C. van der Lubbe, T. C. Ramalho, T. A. Hamlin and F. M. Bickelhaupt, ChemistryOpen, 2021, 10, 391-401; (c) O. Larrañaga, A. Arrieta, C. Fonseca Guerra, F. M. Bickelhaupt and A. de Cózar, Chem. - Asian J., 2021, 16, 315-321.

9 (a) F. M. Bickelhaupt, J. Comput. Chem., 1999, 20, 114-128; (b) W.-J. van Zeist and F. M. Bickelhaupt, Org. Biomol. Chem., 2010, 8, 3118-3127; (c) P. Vermeeren, S. C. C. van der Lubbe, C. Fonseca Guerra, F. M. Bickelhaupt and T. A. Hamlin, Nat. Protoc., 2020, 15, 649-667.

10 (a) F. M. Bickelhaupt and E. J. Baerends, in Reviews in Computational Chemistry, ed. K. B. Lipkowitz and D. B. Boyd, Wiley-VCH, New York, 2000, vol. 15, pp. 1-86; (b) F. M. Bickelhaupt, N. M. M. Nibbering, E. M. van Wezenbeek and E. J. Baerends, J. Phys. Chem., 1992, 96, 4864-4873; (c) A. Krapp, F. M. Bickelhaupt and G. Frenking, Chem. - Eur. J., 2006, 12, 9196-9216; (d) T. A. Hamlin, P. Vermeeren, C. Fonseca Guerra and F. M. Bickelhaupt, in Complementary Bonding Analyses, ed. S. Grabowski, De Gruyter, Berlin, 2021, pp. 199-212.

11 (a) G. te Velde, F. M. Bickelhaupt, E. J. Baerends, C. Fonseca Guerra, S. J. A. van Gisbergen, J. G. Snijders and T. Ziegler, J. Comput. Chem., 2001, 22, 931-967; (b) C. Fonseca Guerra, J. G. Snijders, G. te Velde and E. J. Baerends, Theor. Chem. Acc., 1998, 99, 391-403; (c) ADF2017.103, SCM Theoretical Chemistry; Vrije Universiteit: Amsterdam (The Netherlands); http://www.scm.com.

12 (a) Y. Zhao and D. G. Truhlar, Theor. Chem. Acc., 2008, 120, 215-241; (b) Y. Zhao and D. G. Truhlar, J. Chem. Phys., 2006, 125, 194101.

13 E. van Lenthe and E. J. Baerends, J. Comput. Chem., 2003, 24, 1142-1156.

14 E. van Lenthe, E. J. Baerends and J. G. Snijders, J. Chem. Phys., 1994, 101, 9783-9792.

15 X. Sun, T. M. Soini, J. Poater, T. A. Hamlin and F. M. Bickelhaupt, J. Comput. Chem., 2019, 40, 2227-2233.

16 (a) F. M. Bickelhaupt, N. J. R. van Eikema Hommes, C. Fonseca Guerra and E. J. Baerends, Organometallics, 1996, 15, 2923-2931; (b) C. Fonseca Guerra, J.-W. Handgraaf, E. J. Baerends and F. M. Bickelhaupt, J. Comput. Chem., 2004, 25, 189-210.

17 (a) M. Swart and F. M. Bickelhaupt, J. Chem. Theory Comput., 2006, 2, 281-287; (b) W. J. van Zeist, Y. Ren and F. M. Bickelhaupt, Sci. China: Chem., 2010, 53, 210-215.

18 J.-W. Zou, Y.-J. Jiang, M. Guo, G.-X. Hu, B. Zhang, H.-C. Liu and Q.-S. Yu, Chem. - Eur. J., 2005, 11, 740-751. 